\title{
Field experiments and numerical modeling of mass entrainment in snow avalanches
}

\author{
Betty Sovilla, ${ }^{1}$ Paolo Burlando, ${ }^{2}$ and P. Bartelt ${ }^{1}$ \\ Received 20 August 2005; revised 24 March 2006; accepted 21 April 2006; published 10 August 2006.
}

[1] Snow entrainment alters the speed and hence the run-out distance of avalanches, yet little is known about this significant process. We studied entrainment in snow avalanches using observations from (1) the Swiss Vallée de la Sionne test site, (2) the Italian Pizzac site, (3) catastrophic avalanches that occurred during the winter 1998-1999 in

Switzerland, and (4) a medium-sized spontaneous avalanche that occurred in 2000 in Davos, Switzerland. We determined mass and energy balances for 18 avalanche events. On average, the mass increased by a factor of 4 . The primary mode of entrainment appeared to be frontal ploughing, although entrainment behind the avalanche front was also observed. Step entrainment, where a snow cover layer fractures and is entirely consumed by the avalanche, also occurred. Basal erosion was negligible. Mass availability and snow cover structure were the limiting factors governing entrainment. Other factors such as track topography and avalanche dimension played a secondary role. Using the experimental results, we introduced an entrainment model into a Saint-Venant type flow model where the internal shear deformation of the avalanche is governed by a Bagnold law and the shear stress at the basal layer is treated as a Voellmy fluid. The model with entrainment not only improves the prediction of the velocities and flow heights in comparison to measurements, but also reproduces the variations in run-out distances, which characterize avalanches with similar terminal velocities but different masses.

Citation: Sovilla, B., P. Burlando, and P. Bartelt (2006), Field experiments and numerical modeling of mass entrainment in snow avalanches, J. Geophys. Res., 111, F03007, doi:10.1029/2005JF000391.

\section{Introduction}

[2] The role of entrainment in snow avalanches, especially in large catastrophic events, is the subject of much speculation and yet has only rarely been experimentally investigated. Sovilla et al. [2001] quantified entrainment and deposition masses of small avalanches (volumes less than $2000 \mathrm{~m}^{3}$ ) released at the Italian Monte Pizzac test site. Although these results showed that entrainment is a significant process (the avalanches increased their original mass by up to a factor 9), it was difficult to generalize the results and to apply them to large destructive avalanches of the kind assumed in hazard mapping practice. Further, experimental evidence of the importance of snow mass changes due to entrainment in large avalanches has emerged from the initial tests in Vallée de la Sionne, Switzerland [Vallet et al., 2001] and in Ryggfonn, Norway (D. Issler, personal communication, 2003).

[3] Avalanche dynamics models are used to predict flow velocities, impact pressures, flow depths and run-out dis-

\footnotetext{
${ }^{1}$ Swiss Federal Institute for Snow and Avalanche Research, Davos Dorf, Switzerland.

${ }^{2}$ Institute for Hydromechanics and Water Resources Management, Swiss Federal Institute for Science and Technology (ETHZ), Zurich, Switzerland.

Copyright 2006 by the American Geophysical Union. 0148-0227/06/2005JF000391
}

tances. Presently, some dense-flow models include entrainment [Eglit and Demidov, 2005; Naaim et al., 2003; Sailer et al., 2002; Hungr, 1995; Grigorian and Ostroumov, 1977]; however, the lack of experimental data hinders systematic validation. Therefore models for practical application do not include entrainment. We argue that the introduction of entrainment into avalanche dynamics models will have far-reaching consequences for avalanche practice. First, as we will show, snow entrainment can dramatically change the mass and energy balance of an event. Above all, the predicted velocity along the path and the kinetic energy of the avalanche as it enters the run-out zone will change. This affects run-out distances and has direct consequences for avalanche hazard mapping. Second, entrainment increases the predicted flow heights and volumes of avalanches. Accurate prediction of these values is crucial when dimensioning retaining or deflecting dams as well as in engineering problems where the force distribution over the flow height or clearance height is required. If higher dam heights are required, construction costs increase, perhaps excluding dams from hazard mitigation strategies. In other words, introducing entrainment into calculation procedures may have a large impact on formulating protective strategies, especially in the run-out zone.

[4] How entrainment is eventually included in avalanche dynamics models and guidelines strongly depends on the nature of the physical mechanism (frontal ploughing, basal erosion) controlling the mass influx rates [Gauer and Issler, 
2004; Sovilla, 2004]. It is essential that these physical mechanisms are parameterized with respect to terrain, snow type and snow cover layering before revised guidelines can be drafted. Presently, these relationships are unknown.

[5] Clearly, an experimental foundation regarding entrainment in snow avalanches is required. However, experimental research has been hampered by the capricious timing and magnitude of natural avalanches. In order to determine the mass balance of a catastrophic event both preevent (snow cover height, layering and density) and postevent (avalanche extent, deposit characteristics) information is required. Research costs are prohibitively large and preevent and postevent analysis are often impossible owing to bad weather and secondary avalanche release.

[6] In the following, we present entrainment data of several large avalanches artificially released at the Swiss Vallée de la Sionne and Italian Pizzac test sites [Issler, 1999]. The volume balance, i.e., the entrainment and deposition amounts, were quantified using photogrammetric [Vallet et al., 2001] and manual [Sovilla et al., 2001; Sovilla, 2004] methods. Combined with prevent and postevent density measurements, this provided the necessary information to estimate the mass balance. In addition, shortly after the catastrophic avalanches of winter 1998-1999 in the European Alps, clear weather prevailed and aerial photographs of several large avalanches are available [Gruber and Bartelt, 2001]. Estimates of the entrained mass for these avalanches are similarly reported.

[7] The data (18 avalanche events) are used to calculate avalanche growth indices. These indices allow a systematic comparison of the avalanche events and thus help identify important relationships between mass, terrain and energy. At the Vallée de la Sionne test site [Ammann, 1999], buried FMCW (Frequency Modulated Continuous Wave) radars [Gubler and Hiller, 1984] are used to measure the snow depth and erosion rates as the avalanches passes over the snow cover. This measurement technique has allowed us to identify the primary entrainment mechanisms.

[8] Using the experimental data, we implemented the entrainment model of Grigorian and Ostroumov [1977] into a Saint-Venant type flow model using a Bagnold/ Voellmy type constitutive relationship, the so-called Norem-Irgens-Schieldrop (NIS) model [Norem et al., 1989], which completely describes the internal stress state and basal layer friction. The Vallée de la Sionne avalanches are subsequently back-calculated and the entire mass and energy balance of the events estimated. In this paper, we focus on the application of the one-dimensional model in two-dimensional terrain [Bartelt et al., 1999]; that is, the model solves the one-dimensional equations for mass balance and momentum balance along a defined profile; for each point of the profile the flow width is defined from observations.

\section{Field Observations}

[9] The results presented in this paper are based on 18 avalanches that occurred between 1997 and 2003 at (1) the Swiss Vallée de la Sionne test site (six avalanches) [Gruber et al., 2002; Sovilla et al., 2004], (2) at the Italian Pizzac test site (six avalanches) [Sovilla et al., 2001], (3) extreme avalanches that occurred in Switzerland during the catastrophic
Table 1. Summary of the Avalanche Events for Which Mass Balance Data Were Collected

\begin{tabular}{|c|c|c|c|c|}
\hline Number & Event & Type & Topography & Dimension \\
\hline $\begin{array}{l}1 \\
2 \\
3 \\
4 a, b \\
5 \\
6\end{array}$ & $\begin{array}{c}\text { Avalanct } \\
30.01 .99 \\
10.02 .99 \\
25.02 .99 \\
31.01 .03 \\
05.02 .03 \\
07.02 .03\end{array}$ & $\begin{array}{l}\text { the } \mathrm{Val} \\
\text { mixed } \\
\text { mixed } \\
\text { mixed } \\
\text { mixed } \\
\text { mixed } \\
\text { mixed }\end{array}$ & $\begin{array}{l}\text { la Sionne Sit } \\
\text { mixed } \\
\text { mixed } \\
\text { mixed } \\
\text { mixed } \\
\text { mixed } \\
\text { mixed }\end{array}$ & $\begin{array}{c}\text { large } \\
\text { large } \\
\text { large }^{\mathrm{a}} \\
\text { large } \\
\text { medium } \\
\text { medium }\end{array}$ \\
\hline $\begin{array}{l}7 \\
8 \\
9 \\
10 \\
11 \\
12\end{array}$ & $\begin{array}{r}\text { Avala } \\
05.12 .97 \\
21.12 .97 \\
14.04 .98 \\
28.04 .98 \\
11.01 .99 \\
05.03 .99\end{array}$ & $\begin{array}{l}\text { at the } \\
\text { dense } \\
\text { dense } \\
\text { dense } \\
\text { dense } \\
\text { dense } \\
\text { dense }\end{array}$ & $\begin{array}{r}\text { Pizzac Site } \\
\text { channeled } \\
\text { channeled } \\
\text { channeled } \\
\text { channeled } \\
\text { channeled } \\
\text { channeled }\end{array}$ & $\begin{array}{l}\text { small } \\
\text { small } \\
\text { small } \\
\text { small } \\
\text { small } \\
\text { small }\end{array}$ \\
\hline $\begin{array}{l}13 \\
14 \\
15 \\
16 \\
17\end{array}$ & $\begin{array}{r}\text { Extreme } \\
09.02 .99 \\
22.02 .99 \\
23.02 .99 \\
23.02 .99 \\
25.02 .99\end{array}$ & $\begin{array}{l}n c h e s \\
\text { mixed } \\
\text { mixed } \\
\text { mixed } \\
\text { mixed } \\
\text { mixed }\end{array}$ & $\begin{array}{c}\text { ter } 1998-199 \\
\text { channeled } \\
\text { open slope } \\
\text { open slope } \\
\text { mixed } \\
\text { mixed }\end{array}$ & $\begin{array}{c}\text { large } \\
\text { large }^{\mathrm{a}} \\
\text { large }^{\mathrm{a}} \\
\text { medium }^{\mathrm{a}} \\
\text { large }^{\mathrm{a}}\end{array}$ \\
\hline \multicolumn{5}{|c|}{ Other Avalanches } \\
\hline
\end{tabular}

${ }^{\mathrm{a}}$ Extreme avalanches with the largest known run-out distance; 4a, 4b: the avalanche of 31 January 2003 followed two distinct channels with full independent dynamics; the two arms are studied independently.

winter 1998-1999 (five avalanches) [Eidgenössische Institut für Schnee- und Lawinenforschung, 2000; Sovilla, 2004] and (4) a medium-sized spontaneous avalanche that occurred in 2000 in Davos, Switzerland.

[10] Table 1 summarizes the characteristics of these natural and artificially released avalanches. The data span events of different dimension, type and return period. Avalanches are classified with respect to type (dense or mixed), topography (channeled, open slope or mixed) and dimension: small avalanches having volumes less than $25,000 \mathrm{~m}^{3}$, medium avalanches having volumes between 25,000 and $60,000 \mathrm{~m}^{3}$ and large avalanches having volumes larger than $60,000 \mathrm{~m}^{3}$. Extreme avalanches with the largest known run-out distance are indicated in Table 1 by footnote "a."

\subsection{Mass Balance Measurements}

[11] Both snow pit and photogrammetric measurements along the avalanche path were employed to measure snow cover variations produced by the avalanche passage. Snow pit measurements [Sovilla et al., 2001] provide a detailed picture of the snow cover and avalanche deposits (layering, density and hardness). However, they are time intensive, and field conditions are often hazardous. The avalanche path must be followed from the release zone to the deposition zone (over $1 \mathrm{~km}$ in Vallée de la Sionne). Thus this technique is suitable only for small avalanches where the average volume is of the order of few thousand cubic meters. Snow pit measurements were used to determine the mass balance of the Pizzac and Brämabüel events (avalanches 7-12 and 18, respectively [Sovilla, 2004]).

[12] For large avalanches with volumes upward of $100,000 \mathrm{~m}^{3}$, comprehensive field investigations are imprac- 
tical. For large avalanches we used photogrammetric techniques [Vallet et al., 2001] combined with manual field measurements. Photogrammetry is rapid and noninvasive. Photogrammetric measurements alone were employed to measure the catastrophic avalanches in 1999 (avalanches 13-17); snow volumes (from the difference between the preevent and postevent snow cover surfaces), avalanche contours and release and deposition areas could be determined [Sovilla, 2004]. Both manual and photogrammetric measurements were used to analyze the Vallée de la Sionne avalanches (avalanches 1-6).

[13] The following parameters were determined for each avalanche.

[14] 1. The "mean release fracture depth $d_{0}(\mathrm{~m})$ " is defined as the depth at the slab crown measured perpendicular to the slope.

[15] 2. The "release area $A_{r}\left(\mathrm{~m}^{2}\right)$ " is defined as the area delimited by the crown, the stauchwall (i.e., the lower limit of the release zone) and the slab flanks. It is determined using either the geo-referenced aerial pictures or by field measurements. In one case (avalanche 17) the stauchwall was not recognizable, making it impossible to define this area.

[16] 3. The "avalanche release volume $V_{r}\left(\mathrm{~m}^{3}\right)$ " is defined as the snow volume delimited by the bed surface, the crown, the stauchwall and the flanks.

[17] 4. The "avalanche release mass" or "initial mass $M_{r}(\mathrm{~kg})$ " representing the amount of snow contained in the avalanche release volume. It is calculated from the observed release area $A_{r}$, slab density $\rho_{0}$ and fracture depth $d_{0}$.

[18] 5. The "potential entrainment area $A_{e}\left(\mathrm{~m}^{2}\right)$ " is computed as the area affected by the avalanche passage, excluding the release area $A_{r}$. At the Pizzac site the avalanche width is determined by field measurements. At the Vallée de la Sionne site, it is determined from video analysis and aerial pictures. However, since the avalanches are frequently mixed, it is difficult to define the width of the dense part of the avalanche because it is hidden by the cloud. In this case, the width of the dense part is approximated using a two-dimensional flowing avalanche model [Gruber, 1998] based on the Voellmy fluid constitutive model [Salm, 1993]. The model solves the governing mass and momentum equations using a first-order TVD scheme on triangular grids [Sartoris and Bartelt, 2000]. The grid is generated from a digital terrain model.

[19] 6. The "average entrainment depth $d_{e}(\mathrm{~m})$ " is computed as

$$
d_{e}=\frac{M_{d}-M_{r}}{A_{e} \rho_{e}},
$$

where $\rho_{e}$ is the density of the entrained snow. Calculations are performed assuming that the density of the entrained snow is equal to the density of the released mass. $M_{d}$ is the deposition mass accumulated by the avalanche in the deposition zone. Secondary deposits left by the avalanche along the avalanche path are not taken into account for the definition of $M_{d}$. As a result, the average entrainment depth $d_{e}$ is not the observed snow cover depth entrained by the avalanche but is a balance between this depth and the deposition depth left by the avalanche along the avalanche path.
Table 2. Summary of Measurements of the Avalanches at the Vallée de la Sionne and Monte Pizzac Test Sites

\begin{tabular}{|c|c|c|c|c|c|}
\hline Number & Event & $\begin{array}{c}\text { Average } \\
\text { Velocity, m/s }\end{array}$ & $\begin{array}{c}\text { Maximum } \\
\text { Velocity, m/s }\end{array}$ & $\begin{array}{c}\text { Run-out, } \\
\mathrm{m}\end{array}$ & $\begin{array}{c}\text { Run-up } \\
\text { Depth, }{ }^{\mathrm{a}} \mathrm{m} \\
\end{array}$ \\
\hline \multicolumn{6}{|c|}{ Avalanches at the Vallée de la Sionne Site } \\
\hline 1 & 30.01 .99 & 39.8 & 56.7 & 0 & 1 \\
\hline 2 & 10.02 .99 & 44.2 & 59.8 & $800^{\mathrm{b}}$ & 3 \\
\hline 3 & 25.02 .99 & 49.5 & $\ldots$ & 1400 & 5 \\
\hline $4 a$ & 31.01 .03 & 36.6 & 41.1 & $\ldots$ & 0 \\
\hline $4 \mathrm{~b}$ & 31.01 .03 & 45.2 & 52.9 & 200 & 0 \\
\hline 5 & 05.02 .03 & $\sim 40$ & $\ldots$ & 0 & 1.5 \\
\hline 6 & 07.02 .03 & 40.1 & 55.9 & 0 & 0 \\
\hline \multicolumn{6}{|c|}{ Avalanches at the Mount Pizzac Site } \\
\hline 7 & 05.12 .97 & 11.0 & $\ldots$ & 547 & $\ldots$ \\
\hline 8 & 21.12 .97 & 17.9 & $\ldots$ & 680 & $\ldots$ \\
\hline 9 & 14.04 .98 & 12.3 & $\ldots$ & 530 & $\ldots$ \\
\hline 10 & 28.04 .98 & 7.6 & $\ldots$ & 540 & $\ldots$ \\
\hline 11 & 11.01 .99 & 13.7 & $\ldots$ & 555 & $\ldots$ \\
\hline 12 & 05.03 .99 & 17.6 & $\ldots$ & 753 & $\ldots$ \\
\hline
\end{tabular}

${ }^{\text {a }}$ Run-up depth corresponds to the deposition depth at the bunker.

${ }^{\mathrm{b}}$ Run-out was influenced by an arm coming from an adjacent slope.

\subsection{Instrumentation}

[20] Twelve of the eighteen avalanches occurred at the Vallée de la Sionne and Pizzac test sites, where additional information such as velocities, pressures and flow depths were collected [Sommavilla and Sovilla, 1998; Gruber et al., 2002; Sovilla et al., 2004].

[21] At the Vallée de la Sionne test site, avalanches have large dimensions and are mostly of the mixed type. Videogrammetric-based front velocities [Vallet et al., 2004] are available only for part of the potential flow area. Thus the average front velocities (Table 2) were determined only between the stauchwall and the beginning of the run-out zone at an altitude of $1640 \mathrm{~m}$ a.s.l. The tabulated maximum velocities are based on measurements taken every $5 \mathrm{~s}$.

[22] Flow depths are measured at specific locations along the avalanche path using flow depth sensors and FMCW radars [Gubler and Hiller, 1984]. Six radars are buried in the ground along the avalanche track [Ammann, 1999]. Each radar is pointed upward and covers a vertical cross section of the avalanche during a defined time period. FMCW radars measure the time taken for the emitted signal to return after being reflected from a snow particle or clump. Hence measuring the intensity of the signal and its corresponding height (by conversion of the signal return time) provides information concerning both the avalanche flow depth and the entrainment location and rate. Figure 1 shows a typical FMCW radar measurement where the interaction between the original snow cover and the avalanche can be observed. The horizontal lines on the bottom left represent the snow cover over the radar before the avalanche passage. The horizontal lines are interrupted by the avalanche arrival. Analysis of the different measurements allows for identification of the entrainment mechanisms and the erosion depth and rate. A collection and analysis of these plots for different avalanche events is given by Sovilla [2004].

[23] At the Pizzac test site, avalanches follow a narrow and channelized path. Mostly dense flow avalanches occur. Average avalanche front velocities are determined by measuring the front time passage at six locations uniformly 

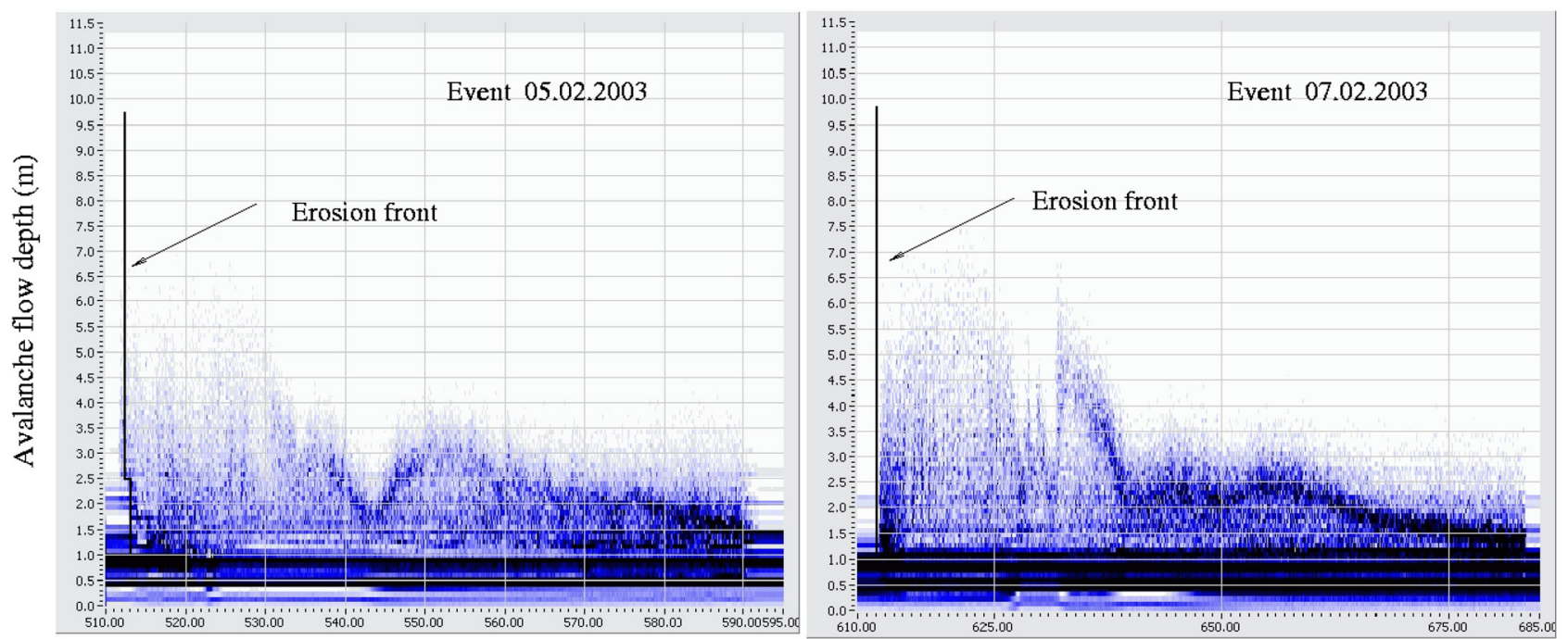

Time $(s)$

Figure 1. FMCW radar plots of the (left) 5 February 2003 and (right) 7 February 2003 avalanches. The radar is positioned at $1892 \mathrm{~m}$ a.s.l. Avalanches plough into the snow cover and slide over a more resistant layer (an old avalanche deposit). The snow cover is entrained at the avalanche front. At the radar location, the 5 February 2003 avalanche entrained almost $1.3 \mathrm{~m}$ of snow while the 7 February avalanche entrained approximately $0.30 \mathrm{~m}$.

distributed along the avalanche path. Average velocities (Table 2) refer to the avalanche velocity between the stauchwall and the end of run-out. Maximum velocities are not measured. Flow depths are measured at the same locations by flow depth sensors [Sommavilla and Sovilla, 1998].

\subsection{Run-Up and Run-Out}

[24] At the Vallée de la Sionne test site avalanches are stopped or deviated by the opposite slope making difficult a precise definition of the run-out. The large avalanches runup the slope to the bunker (about $40 \mathrm{~m}$ above the valley bottom) and partially or totally cover it, while part of the mass is deflected by the slope by nearly $90^{\circ}$ and keeps flowing along the valley.

[25] For these avalanches we define as run-out the distance between the point at an altitude of $1640 \mathrm{~m}$ a.s.l., where avalanches start to decelerate, and the far end of the deposit. However, to distinguish between avalanches that are deviated and avalanches that are stopped by the opposite slope, run-out in Table 2 refers to the distance between the point where the avalanche is deviated and its endpoint. The run-up is characterized by an approximate deposition snow depth at the bunker.

[26] Run-out distances of the Pizzac avalanches are also shown in Table 2. These are defined from the lower limit of the stauchwall.

\section{Analysis of Field Observations}

3.1. Avalanche Mass Balance and Entrainment Indices

[27] Table 3 summarizes the mass balance of the eighteen investigated avalanches. Further details of each avalanche are reported by Sovilla [2004]. Table 3 lists: release area, $A_{r}$, average fracture depth, $d_{0}$, average release density, $\rho_{0}$, release mass, $M_{r}$, average deposit density, $\rho_{d}$, deposit mass, $M_{d}$, and potential entrainment area, $A_{e}$. These values have been used to calculate entrainment depth, $d_{e}$, potential entrainment index, $I_{p e}$, avalanche growth index, $I_{g}$, and entrainment index, $I_{e}$.

[28] The following "entrainment indices" were calculated.

[29] 1. The "growth index $I_{g}$ " defines the avalanche mass increase due to snow entrainment. It is given by the ratio of the deposited mass $M_{d}$ to the released mass $M_{r}$ :

$$
I_{g}=\frac{M_{d}}{M_{r}} .
$$

An index $I_{g}>1$ implies that snow entrainment along the avalanche path has occurred.

[30] 2. The "potential entrainment index $I_{p e}$ " indicates the possible avalanche mass increase

$$
I_{p e}=\frac{A_{e}}{A_{r}} .
$$

It compares the area of entrainment basin $A_{e}$ to the release area $A_{r}$.

[31] 3. The "entrainment index $I_{e}$ " is defined as

$$
I_{e}=\frac{d_{e}}{d_{0}} .
$$

It compares the mean entrainment depth to the mean release fracture depth.

[32] The box-plots of the avalanche indices (Figure 2) and the data (Table 3) allows us to make the following observations. 
Table 3. Summary of the Mass Balance Data Collected at the Vallée de la Sionne and Monte Pizzac Test Sites ${ }^{\mathrm{a}}$

\begin{tabular}{|c|c|c|c|c|c|c|c|c|c|c|c|}
\hline Number & $\begin{array}{c}\text { Release } \\
\text { Area } A_{r}, \mathrm{~m}^{2}\end{array}$ & $\begin{array}{c}\text { Fracture } \\
\text { Depth } d_{0}, \mathrm{~m}\end{array}$ & $\begin{array}{c}\text { Release Density } \\
\rho_{0}, \mathrm{~kg} / \mathrm{m}^{3}\end{array}$ & $\begin{array}{c}\text { Release } \\
\text { Mass } M_{r}, \mathrm{t}\end{array}$ & $\begin{array}{c}\text { Deposit Density } \\
\rho_{d}, \mathrm{~kg} / \mathrm{m}^{3}\end{array}$ & $\begin{array}{c}\text { Deposit } \\
\text { Mass } M_{d}, \mathrm{t}\end{array}$ & $\begin{array}{l}\text { P.e. Area } \\
A_{e}, \mathrm{~m}^{2}\end{array}$ & $\begin{array}{l}\text { Entrainment } \\
\text { Depth } d_{e}, \mathrm{~m}\end{array}$ & $I_{p e}$ & $I_{g}$ & $I_{e}$ \\
\hline \multicolumn{12}{|c|}{ Avalanches at the Vallée de la Sionne Site } \\
\hline 1 & 54,600 & 1.31 & 200 & 14,300 & 350 & 13,800 & 542,000 & -0.05 & 9.9 & $\sim 1$ & -0.04 \\
\hline 2 & 109,200 & 0.77 & 200 & 16,800 & 400 & 202,200 & $1,315,000$ & 0.71 & 12.0 & 12.0 & 0.9 \\
\hline 3 & 210,900 & 1.5 & 200 & 63,300 & 400 & 380,400 & 804,500 & 1.97 & 3.8 & 6.0 & 1.3 \\
\hline $4 a$ & 15,000 & 0.60 & 230 & 2070 & 400 & 15,130 & 195,800 & 0.29 & 13.0 & 7.3 & 0.5 \\
\hline $4 \mathrm{~b}$ & 101,400 & 0.60 & 230 & 13,990 & 400 & 67,800 & 308,300 & 0.76 & 3.0 & 4.8 & 1.25 \\
\hline 5 & 32,600 & 1.12 & 200 & 7300 & 400 & 40,500 & 275,500 & 0.60 & 8.5 & 5.5 & 0.54 \\
\hline 6 & 53,120 & 1.05 & 200 & 11,150 & 400 & 17,160 & 237,000 & 0.13 & 4.5 & 1.5 & 0.12 \\
\hline \multicolumn{12}{|c|}{ Avalanches at the Mount Pizzac Site } \\
\hline 7 & 1000 & 0.25 & 135 & 33.8 & 280 & 61.6 & 2780 & 0.08 & 2.8 & 1.8 & 0.3 \\
\hline 8 & 1490 & 0.40 & 140 & 84.5 & $270 \div 430$ & 505.9 & 6630 & 0.45 & 4.4 & 6.0 & 1.1 \\
\hline 9 & 600 & 0.45 & 115 & 31.1 & $290 \div 345$ & 126.8 & 3830 & 0.22 & 6.4 & 4.1 & 0.5 \\
\hline 10 & 600 & 0.30 & 500 & 90.0 & $500 \div 560$ & 296.7 & 3780 & 0.11 & 6.3 & 3.3 & 0.4 \\
\hline 11 & 800 & 0.50 & 100 & 40.0 & $240 \div 340$ & 167.4 & 5150 & 0.25 & 6.4 & 4.2 & 0.5 \\
\hline 12 & 830 & 0.40 & 160 & 53.1 & $200 \div 375$ & 468.2 & 6230 & 0.42 & 7.5 & 8.8 & 1.0 \\
\hline \multicolumn{12}{|c|}{ Extreme Avalanches of Winter 1998-1999 } \\
\hline 13 & 60,200 & 2.00 & 200 & 24,080 & 400 & 109,100 & 298,500 & 1.40 & 5.0 & 4.5 & 0.70 \\
\hline 14 & 85,800 & 2.00 & 200 & 34,320 & 400 & 85,600 & 470,750 & 0.55 & 5.5 & 2.5 & 0.30 \\
\hline 15 & 80,200 & 2.00 & 200 & 32,080 & 400 & 134,900 & 393,700 & 1.30 & 4.9 & 4.2 & 0.65 \\
\hline 16 & 28,100 & 2.00 & 200 & 11,240 & 400 & 49,700 & 163,250 & 1.20 & 5.8 & 4.4 & 0.60 \\
\hline 17 & $\cdots$ & 1.35 & 200 & $\ldots$ & 400 & 224,300 & $\ldots$ & $\cdots$ & $\ldots$ & $\ldots$ & $\ldots$ \\
\hline \multicolumn{12}{|c|}{ Others Avalanches } \\
\hline 18 & 45,200 & 0.4 & 200 & 3600 & 440 & 6250 & 66,000 & 0.2 & 1.5 & 1.7 & 0.5 \\
\hline
\end{tabular}

a Table also includes catastrophic avalanches of the winter 1998-1999 and a medium-sized spontaneous avalanche that occurred in Davos, Switzerland, in 2000. Avalanche indices are listed: potential entrainment index, $I_{p e}=A_{e} / A_{r}$; growth index, $I_{g}=M_{d} / M_{r}$; and entrainment index, $I_{e}=d_{e} / d_{0}$.

[33] 1. The 18 avalanches were characterized by potential entrainment indices $I_{p e}$ varying between $1.5<I_{p e}<13$ with a mean value of 6 .

[34] 2. The growth index $I_{g}$ varies significantly $\left(1<I_{g}<12\right)$. On average, the avalanches increased their mass by a factor $I_{g}=4.6$.

[35] 3. At the Vallée de la Sionne site the growth index varied between $1<I_{g}<12$; at the Pizzac site between $1.8<$ $I_{g}<8.8$. Thus, at the same site, entrainment can vary significantly. This suggests that terrain characteristics are not the most important cause for entrainment.

[36] 4. Extreme avalanches gained mass substantially, as in the case of the Vallée de la Sionne event of 25 February $1999\left(I_{g}=6.0\right)$, or only slightly, as in the case of the avalanches of the Obergoms Valley (minimum value $I_{g}=$ 2.5). Both large and small avalanches increased their mass. This suggests that entrainment does not depend strongly on avalanche size.

[37] 5. The index $I_{e}$ varied between $\left(-0.04<I_{e}<1.25\right)$. On average avalanches entrained a snow depth $d_{e}=0.6 d_{0}$ along the avalanche path. Avalanche 1 in Table 3 has a negative entrainment index. A previous event [Gruber et al., 2002] entrained all the snow along the avalanche path; moreover, in spite of the large potential erosion area, avalanche 1 did not have snow to entrain. Rather, it lost mass along the avalanche path. This is a typical situation when multiple events occur. A similar situation was observed for avalanche 6 . In this case, however, the avalanche maintained a positive mass balance.

\subsection{Avalanche Energy Balance}

[38] We determined the potential energies of the release and entrainment zones to investigate the role of entrainment in the avalanche energy balance. The photogrammetric measurements made at the Vallée de la Sionne test site (Table 3) were used to approximate the avalanche potential energy, which is given by

$$
P_{r}=M_{r} g \bar{H}_{r},
$$

where $g$ is the gravitational acceleration and $\bar{H}_{r}$ is the average height of the release zone measured with respect to

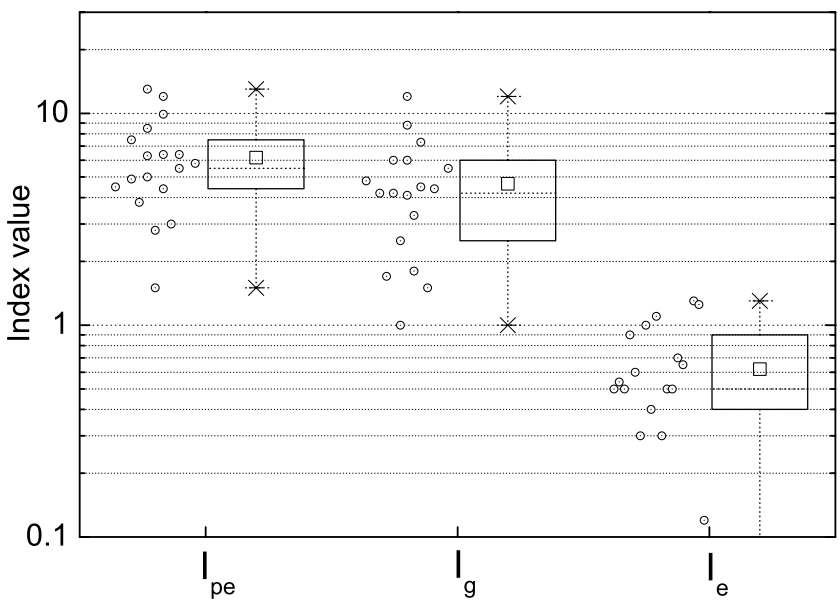

Figure 2. Summary of entrainment indices: potential erosion index, $I_{p e}$, growth index, $I_{g}$, and entrainment index, $I_{e}$. The box plots show the mean (square in box), median (line in box), 25/75\% quantiles (box), 5/95\% quantiles (whiskers), and $0 / 100 \%$ quantiles (cross). On the left of each box plot the measurement distribution is also shown. The negative value $I_{e}=-0.04$ is not displayed. 


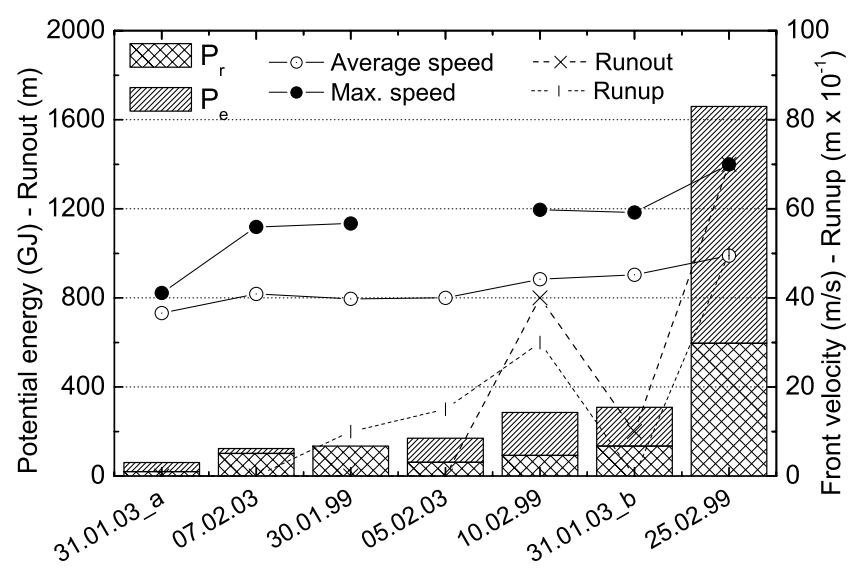

Figure 3. Vallée de la Sionne avalanches. Potential energy of the released $P_{r}$ and entrained $P_{e}$ masses at $1640 \mathrm{~m}$ a.s.l. Average velocities (white dots), maximum front velocities (black dots), run-out (crosses), and run-up (vertical segments) for each event are also shown.

the altitude of $H_{0}=1640 \mathrm{~m}$ a.s.l. This value is compared to the potential energy of the entrained snow given by

$$
P_{e}=M_{e} g \bar{H}_{e}
$$

where $\bar{H}_{e}$ is the average height of the entrainment zone with respect to $H_{0}$. The values of $P_{r}$ and $P_{e}$ are shown in Figure 3. There are only two avalanche events (7 February 2003 and 30 January 1999) where $P_{r}>P_{e}$. For these two events, previous avalanches entrained the snow cover, clearing the track. However, the usual case was that the entrainment potential energy was slightly larger than the release potential energy. For these events, neglecting the entrainment mass results in a factor 2 error in the energy definition of the avalanche.

[39] Although the potential energies of the events vary, the front velocities do not change significantly (Figure 3). For example, the massive avalanche of 25 February 1999 has a higher total potential energy than the other events, but nearly the same average front velocity. Evidently, the magnitude of the front velocity is not dependent on where the mass comes from (the release zone or the entrainment zone). However, Figure 3 does not provide information where the avalanche attains its maximum velocity. This point will be examined in the following sections where the kinetic energy of the avalanche is determined using a numerical model.

[40] The Vallée de la Sionne avalanches have similar velocities, yet completely different run-out and run-up distances (Table 2). Evidently, these avalanches reach similar terminal flow velocities, approximately $45 \mathrm{~m} / \mathrm{s}$, although they have different potential energies. The higher the potential energy, the longer the run-out distance. The avalanche of 31 January 2003 is an exception to this trend because it was the first avalanche of the season (rough sliding surface) and it turned before climbing the run-up slope.

[41] Potential energies for the six Pizzac avalanches (Figure 4) are calculated with respect to the altitude $H_{0}=$ $1900 \mathrm{~m}$ a.s.1. Four of the avalanches in Figure 4 are small events that stopped very close to the altitude of $1900 \mathrm{~m}$ a.s.1. For these avalanches, $P_{r}>P_{e}$ and the total energy was not large enough to pass over a flat part of track where these avalanches stopped.

[42] Only two of the observed avalanches reached the bottom of the valley, and in these cases the entrainment potential energy was more than 2 times larger than the release potential energy. Neglecting the entrained mass results in a factor of 3 error in the energy balance for these events.

[43] Only two of the Pizzac avalanches reached terminal flow velocities of about $18 \mathrm{~m} / \mathrm{s}$. The two avalanches had comparable energy, although the avalanche of 5 March 2003 had a longer run-out because of an icy and therefore smooth sliding surface (Figure 4). It was the only avalanche to develop a powder flow component that traveled a long distance [Sovilla, 2004].

\subsection{Entrainment Mechanisms}

[44] The interaction between avalanche and snow cover observed using FMCW radar at the Vallée de la Sionne experimental site allow the definition of three main entrainment mechanisms: frontal entrainment or ploughing, step entrainment and basal erosion [Sovilla, 2004]. Frontal entrainment or ploughing occurs when the snow cover is characterized by dry, low-density and cohesionless snow. Avalanches tend to dive into the snow cover and slide over a more resistant and older layer or even on the ground. In this case, frontal impact between the avalanche front and the snow cover takes place. Figure 1 shows two examples of frontal entrainment. In these cases the resistant layer over which the avalanche slides is an old avalanche deposit. The snow cover is entrained at the avalanche front in a very short time (typical duration 0.1-2 s). Ploughing entrainment rates depend directly on the depth and density of the snow cover and the speed of the avalanche. In Vallée de la Sionne, ploughing entrainment rates up to $350 \mathrm{~kg} /\left(\mathrm{m}^{2} \mathrm{~s}\right)$ were measured.

[45] Step entrainment occurs when the snow cover is characterized by low-strength snow layers sandwiched between ice/snow crusts. Initially, the avalanche slides over a resistant surface, typically an ice crust. If the crust breaks,

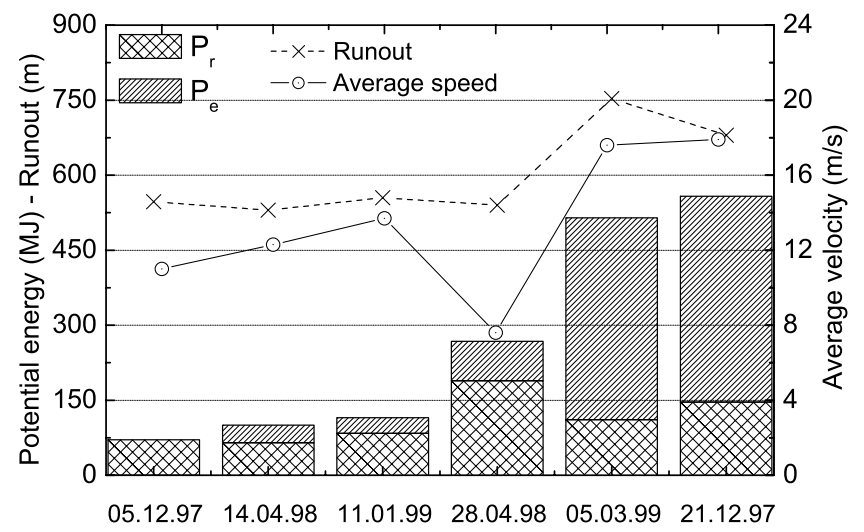

Figure 4. Pizzac avalanches: potential energy of the released $P_{r}$ and entrained $P_{e}$ masses at $1900 \mathrm{~m}$ a.s.l. Average velocities (white dots) and run-out distances (crosses) for each event are also shown. 


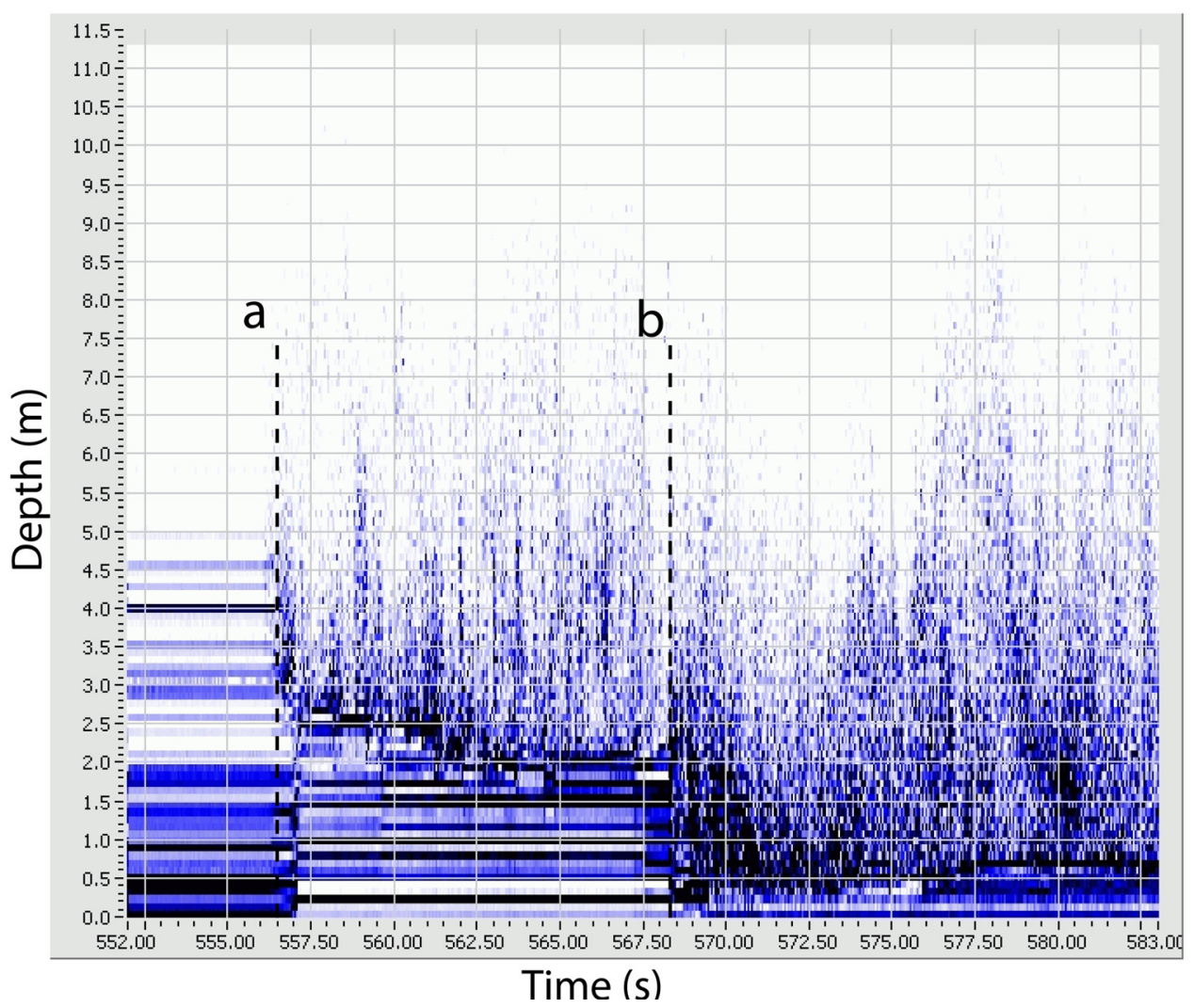

Figure 5. FMCW radar plot measured on 27 December 1999. The avalanche entrains part of the snow cover immediately at the front (front entrainment). Between sections a and $\mathrm{b}$, there is no evident sliding surface and the avalanche ploughs progressively into the snow cover (basal erosion). At section b, about $1.5 \mathrm{~m}$ of snow are instantaneously entrained (step entrainment).

the sliding surface of the avalanche changes abruptly and the weaker snow below the crust is immediately entrained. Analogous to the ploughing case, a large amount of snow suddenly enters the avalanche, but the location is no longer directly at the front. At each change of sliding surface a frontal impact between snow cover and avalanche occurs as in the ploughing case. The entrainment rate depends on the snow cover characteristics; as in the case of the frontal ploughing, it can reach very high values, up to $350 \mathrm{~kg} /\left(\mathrm{m}^{2} \mathrm{~s}\right)$ at the Vallée de la Sionne. Figure 5 shows an example of this mechanism. In this case about $1.5 \mathrm{~m}$ of snow are entrained almost instantaneously.

[46] Basal erosion occurs when the snow cover contains layers with high shear strength. Typical examples of high strength snow are melt-freeze layers, high-density snow composed of small faceted and rounded crystals, old ava- lanche deposits and snow with a high water content. In basal erosion, the avalanche scrapes mass from the sliding surface in proportion to the shearing force that the avalanche exerts on the basal surface. In this case, entrainment rates are low, up to $10 \mathrm{~kg} /\left(\mathrm{m}^{2} \mathrm{~s}\right)$. These rates are a factor of 10 smaller than the observed ploughing entrainment rates. The snow is entrained in the avalanche interior, behind the front. The entrainment is not instantaneous, and its duration can strongly vary. Measured time intervals are between 1 and $40 \mathrm{~s}$. While this process can take much more time than the other two mechanisms, the amount of eroded snow can be considered comparable. However, this entrainment process distributes the entrained mass over a large part of the avalanche length. Sometimes, basal erosion will even occur in the tail of the avalanche with smaller effects on the avalanche dynamics. An example of this mechanism is

Table 4. Summary of the Main Entrainment Mechanisms: Ploughing Entrainment, Step Entrainment, and Basal Erosion

\begin{tabular}{|c|c|c|c|}
\hline & Ploughing & Step Entrainment & Basal Erosion \\
\hline Main features & frontal entrainment & $\begin{array}{l}\text { rapid change of sliding surface, } \\
\text { evident step }\end{array}$ & no evident sliding surface \\
\hline Location & front & interior & interior \\
\hline Time scale & $0.1 \div 2 \mathrm{~s}$ & $0.1 \div 2 \mathrm{~s}$ & $1 \div 410 \mathrm{~s}$ \\
\hline Governing mechanism & frontal impact & frontal impact & shear stress \\
\hline Entrainment rate & up to $350 \mathrm{~kg} /\left(\mathrm{m}^{2} \mathrm{~s}\right)$ & up to $350 \mathrm{~kg} /\left(\mathrm{m}^{2} \mathrm{~s}\right)$ & up to $10 \mathrm{~kg} /\left(\mathrm{m}^{2} \mathrm{~s}\right)$ \\
\hline $\begin{array}{l}\text { Snow cover } \\
\text { characteristics }\end{array}$ & $\begin{array}{l}\text { low density and } \\
\text { cohesionless snow }\end{array}$ & $\begin{array}{l}\text { low strength snow sandwiched } \\
\text { between thin ice/snow crusts }\end{array}$ & $\begin{array}{l}\text { ice crust, high strength snow layer, } \\
\text { old avalanche deposits }\end{array}$ \\
\hline Layer shear strength & $p^{*}<1 \mathrm{kPa}$ & $1<p^{*}<25 \mathrm{kPa}$ & $p^{*}>25 \mathrm{kPa}$ \\
\hline
\end{tabular}




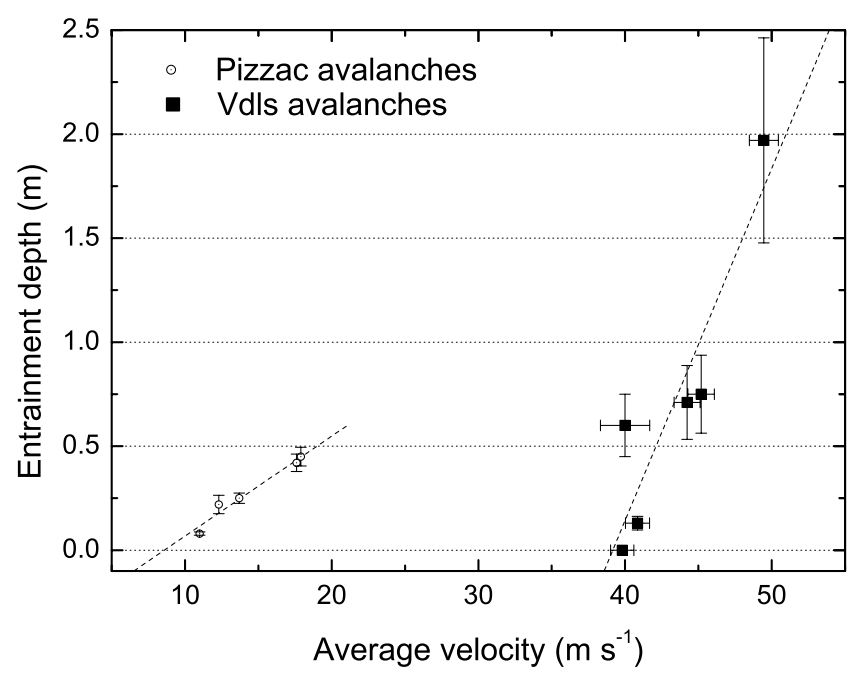

Figure 6. Pizzac and Vallée de la Sionne avalanches. The entrainment depth is plotted as a function of the average avalanche front velocity.

shown in Figure 5 where the avalanche entrains about $0.30 \mathrm{~m}$ of snow in about $10 \mathrm{~s}$.

[47] Table 4 summarizes the different entrainment processes. Different entrainment mechanisms lead to different entrainment rates: frontal and step entrainment have the highest influx rates. Entrainment rates are limited by mass availability. This fact can be experimentally verified by correlating the measured entrainment depth and avalanche average velocity (Figure 6). The entrainment depth increases linearly with the average avalanche front velocity. However, Figure 6 shows that for the Pizzac and Vallée de la Sionne avalanches, which are of completely different size, similar entrainment depths do not correspond to similar velocities. For example, $0.4 \mathrm{~m}$ of snow are entrained at the Pizzac test site by avalanches having velocities of about $17 \mathrm{~m} / \mathrm{s}$. At the Vallée de la Sionne test site the avalanches entrain $0.5 \mathrm{~m}$ but have velocities of about $42 \mathrm{~m} / \mathrm{s}$. Thus, although a linear relationship between velocity and entrainment depth exists, it cannot fully explain the absolute entrained mass in real avalanches which is controlled primarily by the availability of snow (snow cover depth and strength) and not by the velocity of the avalanche.

\section{Entrainment Model}

[48] The entrainment mechanism discussed in the previous section can be conceptualized in a mathematical model. In this paper we use the model proposed by Grigorian and Ostroumov [1977].

[49] Consider an avalanche that is moving downslope with a velocity $U(x, t)$ at time $t$. The $x$ coordinate defines the position of the avalanche along the slope. The mean flowing density of the avalanche is $\rho_{a}$; the height of the avalanche $h(x, t)$ varies with $x$ and $t$.

[50] The track is covered with an $n$-layered snowpack (see Figure 7). The total height and unit mass (per $\mathrm{m}^{2}$ ) of the snow cover for any time $t$ and position $x$ are given by

$$
\begin{gathered}
H_{s}(x, t)=\sum_{i=1}^{n} h_{s i}(x, t) \\
M_{s}(x, t)=\sum_{i=1}^{n} \rho_{s i}(x) h_{s i}(x, t),
\end{gathered}
$$

where $h_{s i}(x, t)$ and $\rho_{s i}(x)$ are the height and density of the $i$ th snow layer. The avalanche is entraining the snow cover, possibly all layers simultaneously but with different rates and positions along the track. The avalanche applies a stress $p(x, t)$ to the layer, and if $p(x, t)$ is greater than the layer strength $p_{i}^{*}(x)$, then part, or perhaps all, of the layer is entrained. The mechanical resistance $p_{i}(x)$ of the $i$ th layer depends on the texture of the layer. Large differences in strength can exist, with new snow having little resistance $p_{i}^{*}(x) \approx 0$.

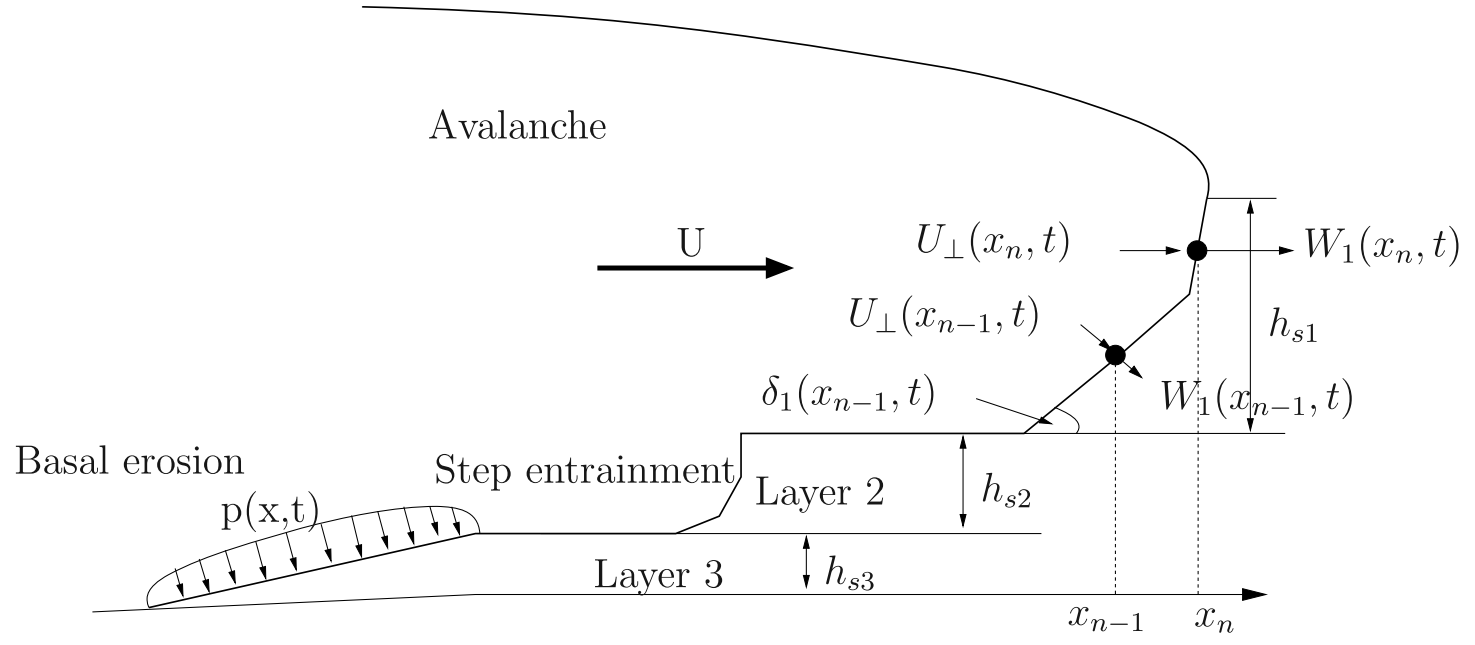

Figure 7. Graphic sketch of the numerical entrainment procedure. Ploughing entrainment is occurring at the front. Step entrainment and bed erosion occur behind the front. 
[51] The mass total entrainment rate is given by

$$
\dot{M}_{e}(x, t)=\sum_{i=1}^{n} \rho_{s i} W_{i}(x, t)
$$

where $W_{i}(x, t)$ is the speed the snow enters the avalanche. The direction of the entrainment velocity is not necessarily parallel to the avalanche flow velocity $U(x, t)$; it is perpendicular to the entrainment front defined by the abrasion angle $\delta_{i}(x, t)$ which may vary from layer to layer (Figure 7).

[52] Mass and momentum conservation for each layer requires that [Grigorian and Ostroumov, 1977; Eglit and Demidov, 2005]

$$
\begin{gathered}
W_{i}(x, t) \rho_{s i}(x)=\left[W_{i}(x, t)-U_{\perp}(x, t)\right] \rho_{a} \\
W_{i}(x, t) U_{\perp}(x, t) \rho_{a}=\left\{\begin{array}{ll}
p(x, t)-p_{i}^{*}(x) & \text { if } p(x, t)>p_{i}^{*}(x) \\
0 & \text { if } p(x, t) \leq p_{i}^{*}(x)
\end{array},\right.
\end{gathered}
$$

where $U_{\perp}(x, t)$ is the avalanche velocity perpendicular to the erosion front. The conservation equations allow us to find the entrainment velocity as a function of the applied pressure and the resistance of the snow cover

$$
W_{i}(x, t)=\sqrt{\frac{p(x, t)-p_{i}^{*}(x)}{\rho_{s i}(x)\left(1-\frac{\rho_{s i}(x)}{\rho_{a}}\right)}} .
$$

This formulation can treat all three observed entrainment mechanisms.

[53] When the snow has no resistance, $p_{i}^{*}(x)=0$, the calculated entrainment rates are between $3000-$ $4000 \mathrm{~kg}\left(\mathrm{~m}^{2} \mathrm{~s}\right)$ (assuming a snow cover density of $100 \mathrm{~kg} / \mathrm{m}^{3}$ and an avalanche velocity between 10 and $20 \mathrm{~m} / \mathrm{s}$ ). Thus, in the extreme case of no snow cover resistance, the calculated frontal ploughing entrainment rates are too large. Of course, nonzero values of $p_{i}^{*}(x)$ can be found that provide good agreement to the observations.

[54] Step entrainment can be modeled by defining a snow cover with a thin ice crust above a larger weak snow layer. The ice crust must have a large resistance. The model can treat step entrainment because of the multilayer formulation. Basal erosion can be modeled by defining intermediate values of $p_{i}^{*}(x)$ between the frontal ploughing and ice-layer cases.

[55] Because the numerical model calculates an avalanche velocity $U(x, t)$ which varies as a function of position $x$ and time $t$, the entrainment rates are also a function of $x$ and $t$. This leads to erosion front angles $\delta_{i}(x, t)$ which can vary between the leading edge and the body of the avalanche (Figure 7).

\section{A Cohesionless Dense Snow Avalanche Model with Multilayer Entrainment}

[56] Bartelt et al. [1999] developed a quasi one-dimensional, depth-averaged numerical model to predict run-out distances, flow heights and velocities of dense flowing avalanches in general terrain. The differential equations governing mass and momentum conservation are solved using second-order TVD schemes [Sartoris and Bartelt, 2000]. This model has been modified to include (1) mass entrainment and deposition and (2) a fully fluidized, cohesionless constitutive model describing dry snow flows in simple shear. The constitutive model was originally formulated by Norem et al. [1989].

[57] We begin with the mass balance

$$
\frac{\partial A}{\partial t}+\frac{\partial Q}{\partial x}=\dot{S}_{e}-\dot{S}_{d}
$$

where $x$ is the length along the avalanche path; $t$ is the time; $A(x, t)$ is the cross-sectional flow area given by $A(x, t)=$ $w(x) h(x, t) ; w(x)$ is the known flow width; $h(x, t)$ is the avalanche flow height; and $Q(x, t)$ is the depth-averaged discharge flow corresponding to the average velocity $U(x, t)$ through the cross section area $A(x, t)$, i.e., $Q(x, t)=A(x, t)$ $U(x, t)$. The right-hand side of equation (13) contains the volumetric snow entrainment $\dot{S}_{e}$ and deposition $\dot{S}_{d}$ rates. In the original version of the model these terms were set equal to zero assuming constant avalanche mass [Bartelt et al., 1999]. The mass loss to the powder cloud will be neglected. See Figure 8 for a definition of the coordinate system and the flow variables.

[58] The momentum balance equation is

$$
\frac{\partial Q}{\partial t}+\frac{\partial}{\partial x}\left[\alpha \frac{Q^{2}}{A}\right]+\lambda g A\left[\frac{\partial h}{\partial x}\right] \cos \varphi=A g \sin \varphi-\operatorname{sgn}(U) A g F_{f}
$$

where $g$ is the acceleration due to gravity; $\varphi(x)$ is the inclination of the track segment; $\alpha(x, t)$ is the velocity profile factor; $\lambda$ is the normal pressure coefficient; and $F_{f}$ is the flow friction slope.

[59] The constitutive model for flowing snow of Norem et al. [1989] is applied. The constitutive equations are

$$
\begin{aligned}
& \tau_{x z}=c+b p_{e}+\rho m_{x y} \dot{\gamma}^{n} \\
& \sigma_{x}=-\left(p_{e}+p_{u}\right)+\rho\left(m_{x x}-m_{z z}\right) \dot{\gamma}^{n} \\
& \sigma_{z}=-\left(p_{e}+p_{u}\right)-\rho m_{z z} \dot{\gamma}^{n} \\
& \sigma_{y}=-\left(p_{e}+p_{u}\right) \\
& \tau_{y z}=\tau_{y x}=0,
\end{aligned}
$$

where $c$ is the snow cohesion $\left(\mathrm{N} / \mathrm{m}^{2}\right), b$ is the dry friction coefficient; $p_{e}$ is the effective pressure $\left(\mathrm{N} / \mathrm{m}^{2}\right) ; p_{u}$ is the pore pressure $\left(\mathrm{N} / \mathrm{m}^{2}\right), \rho$ is the flow density $\left(\mathrm{kg} / \mathrm{m}^{3}\right), m_{x y}$ is the shear viscosity $\left(\mathrm{m}^{2} \mathrm{~s}^{n-2}\right) ; m_{x x}, m_{z z}$ are the normal stress viscosities $\left(\mathrm{m}^{2} \mathrm{~s}^{n-2}\right)$ and $\dot{\gamma}$ is the equivalent shear rate.

[60] The dilatant nature of the flow is evident in the constitutive equations since the shear and normal stresses 


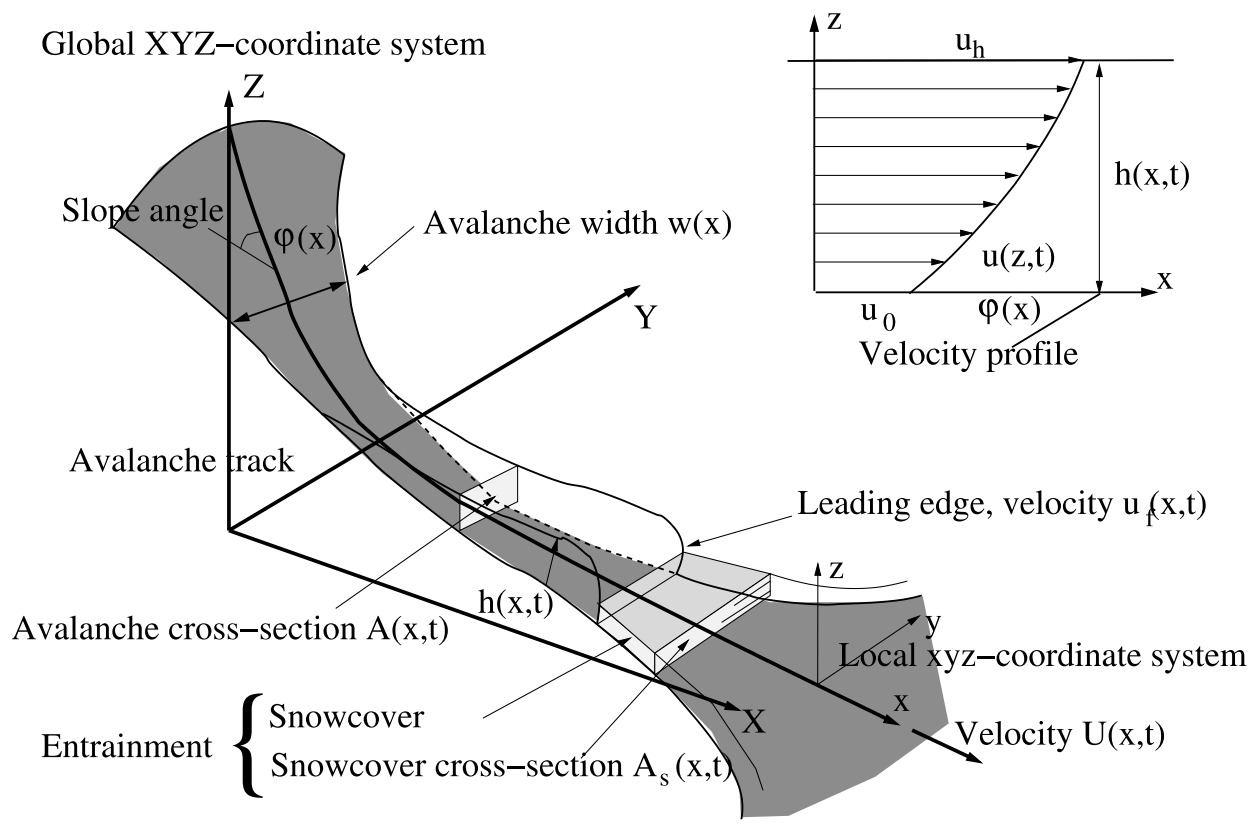

Figure 8. Definition of the coordinate system and flow variable.

are related to square of the shear deformation rate $(n=2)$. In steady state the shear rate in the avalanche body is given by

$$
\dot{\gamma}=\frac{\partial U}{\partial z}=\frac{3}{2} \frac{\left(u_{h}-u_{0}\right) \sqrt{1-\frac{z}{h}}}{h},
$$

where $u_{0}$ is the velocity at the base of the avalanche and $u_{h}$ the velocity at the top surface, (see inset Figure 8) since there exists only one velocity profile in steady state that satisfies the force equilibrium between the driving and resisting forces. This fact has been used to analyze the results from large-scale chute experiments with snow where shear deformation profiles were measured with optical velocity sensor arrays [Tiefenbacher and Kern, 2004]. The analysis showed that $n=2$ acceptably fits the measured velocity distribution in the basal shear layer [Kern et al., 2004].

[61] The above listed constitutive relations provide a complete description of avalanching snow on slip running surfaces, $u_{0} \neq 0$. Chute experiments show significant slip velocities. In this model, the basal shear stress, and subsequently the degree of slip, is regulated by a Voellmy-Salm type equation

$$
\tau_{x z}(0)=-b \sigma_{z}(0)+s u_{0}^{2}
$$

where $s$ is the coefficient of viscous sliding $\left(\mathrm{kg} / \mathrm{m}^{3}\right)$. Thus resistance at the basal surface is the sum of a Coulomb-like friction and a velocity squared dependent friction. The parameter $s$ is a measure of the surface roughness of the terrain [Salm, 1993] whereas the Coulomb friction parameter is given by snow-on-snow sliding [Dent, 1993]. The friction slope is found by depth integration of the shear stress gradient,

$$
F_{f}=b \cos \varphi+\frac{s u_{0}^{2}}{\rho g h} .
$$

[62] In the following, a fully fluidized, cohesionless $(c=0)$, dry-snow avalanche flow is assumed. The degree of fluidization is given by the factor $R$,

$$
R=\frac{u_{h}}{u_{0}}=\left[1+\frac{2 h}{3} \sqrt{\frac{s}{\rho\left(m_{x z}-b m_{z z}\right)}}\right] \text {, }
$$

defined as the ratio between the velocity at the top flow surface $u_{h}$ and the slip velocity $u_{0}$. A smooth surface implies $s=0$; thus the avalanche will remain in a plug-flow regime, i.e., $R=1$. Full-fluidization of the avalanche body, $R>1$, is based on the observations of Gubler [1987], who noted that once the fracture mass has passed the stauchwall there is a rapid increase in viscous friction, due to fluidization of the dense core. In the early stages of motion, just after slab release, (e.g., $100 \mathrm{~m}$ from the fracture line) the flow contains large fractured snow blocks whose motion is governed by sliding Coulomb-like friction alone. This stage of the avalanche motion can be modeled by setting $s=0$.

[63] The effective pressure $p_{e}$ is found assuming that the stress in the $z$ direction is hydrostatic. Hence

$$
\sigma_{z z}=\rho g(h-z) \cos \varphi=-\left(p_{e}+p_{u}\right)+\rho m_{z z} \dot{\gamma}^{2}
$$

from which

$$
p_{e}=-\rho g(h-z) \cos \varphi+\frac{9 \rho m_{z z}}{4 h^{2}}\left(u_{h}-u_{0}\right)^{2}\left(1-\frac{z}{h}\right)
$$

assuming the pore pressures are small in comparison to the hydrostatic pressure, a reasonable but as yet unverified assumption. The normal pressure coefficient $\lambda$ governs the amount of longitudinal stress introduced via normal straining of the flow body [Salm, 1993; Bartelt et al., 1999]. It is found by applying the definition of effective 


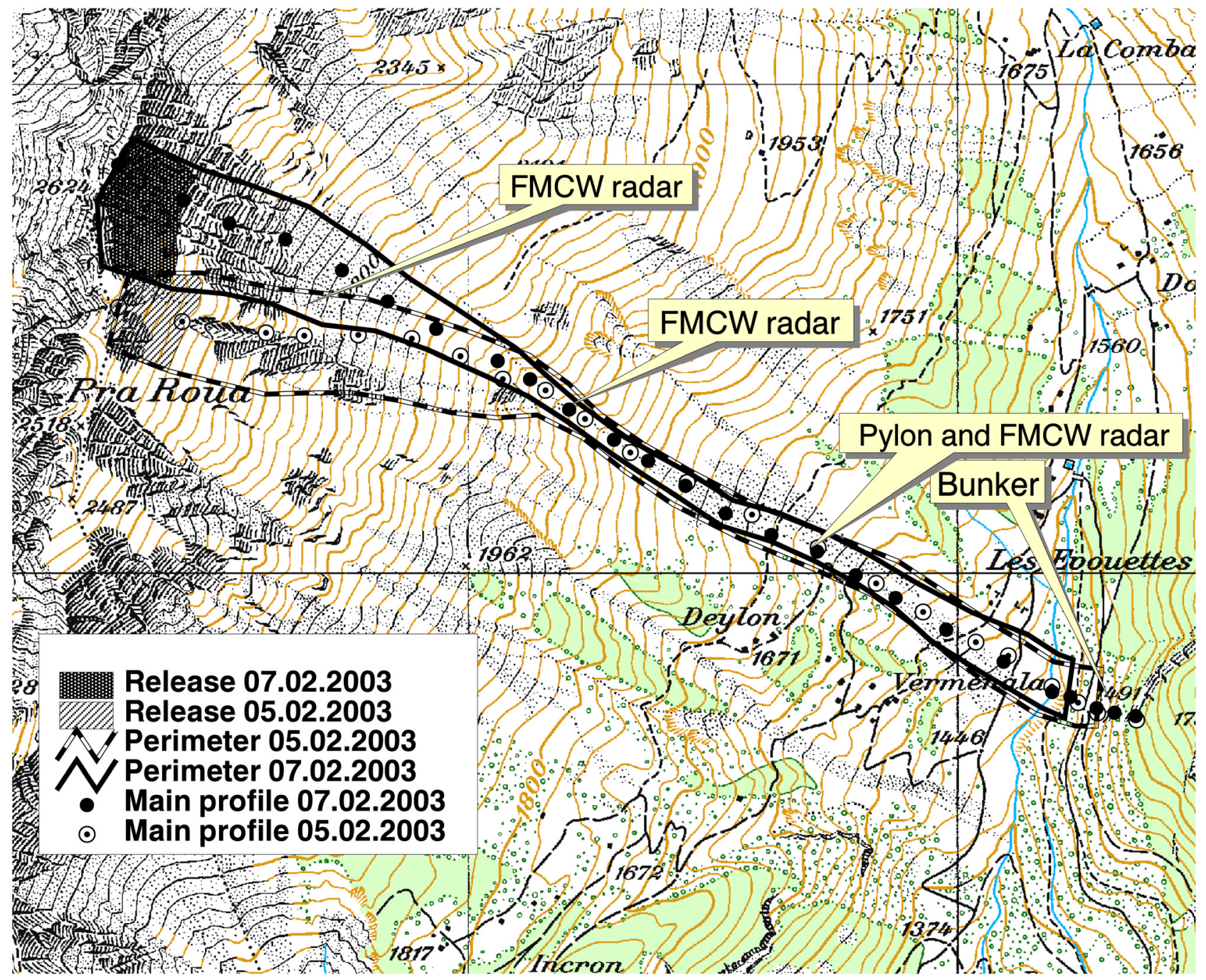

Figure 9. Overview of the de Vallée la Sionne events of 5 and 7 February 2003. Avalanches followed a similar trajectory.

pressure $p_{e}$ and then depth-averaging the normal stress gradient,

$$
\lambda=\left[1+\frac{9 m_{x x}\left(u_{h}-u_{0}\right)^{2}}{8 g h^{3} \cos \varphi}\right] .
$$

The model does not distinguish between active and passive flow states [Salm, 1993].

[64] The fracture slab and the snow cover define the initial mass conditions of the model

$$
A(x, 0)=A_{0}=d_{0}(x) w(x) \text { for } 0 \leq x \leq L,
$$

where $L$ is the length of the slab, which has initial crosssectional area $A_{0}$ and $d_{0}$ defines the fracture slab height. The initial snow cover is defined according to

$$
A_{s}(x, 0)=\left(\sum_{i=1}^{n} h_{s i}(x)\right) w(x) \quad \text { for } \quad L \leq x \leq E
$$

where $n$ is the number of snow layers at track position $x$ in the snowpack and $h_{s i}$ is the height of the $i$ th layer. $E$ represents the $x$ coordinate of the end of the avalanche track. The volumetric snow entrainment rate $\dot{S}_{e}$ is computed using equation (9). However, the calculation of $\dot{S}_{e}$ occurs at the layer level. Depending on the snow cover properties, either part of the layer, an entire layer or multiple layers can be entrained.

[65] In the entrainment algorithm the slip velocity $u_{0}(x, t)$ of the avalanche is used to define the pressure $p(x, t)$ and therefore the entrainment velocity $W(x, t)$ (equation (12)). The slip velocity $u_{0}(x, t)$ is always smaller than the mean velocity of the avalanche. The entrainment conditions of each layer, beginning at layer $n$, are checked. Should an entire layer be entrained, then the next layer is checked. The numerical procedure continually updates the snow cover height at track position $x$ between time $t$ and $t+d t$ according to

$$
A_{s}(x, t+d t)=A_{s}(x, t)-\dot{S}_{e}(x, t) d t .
$$




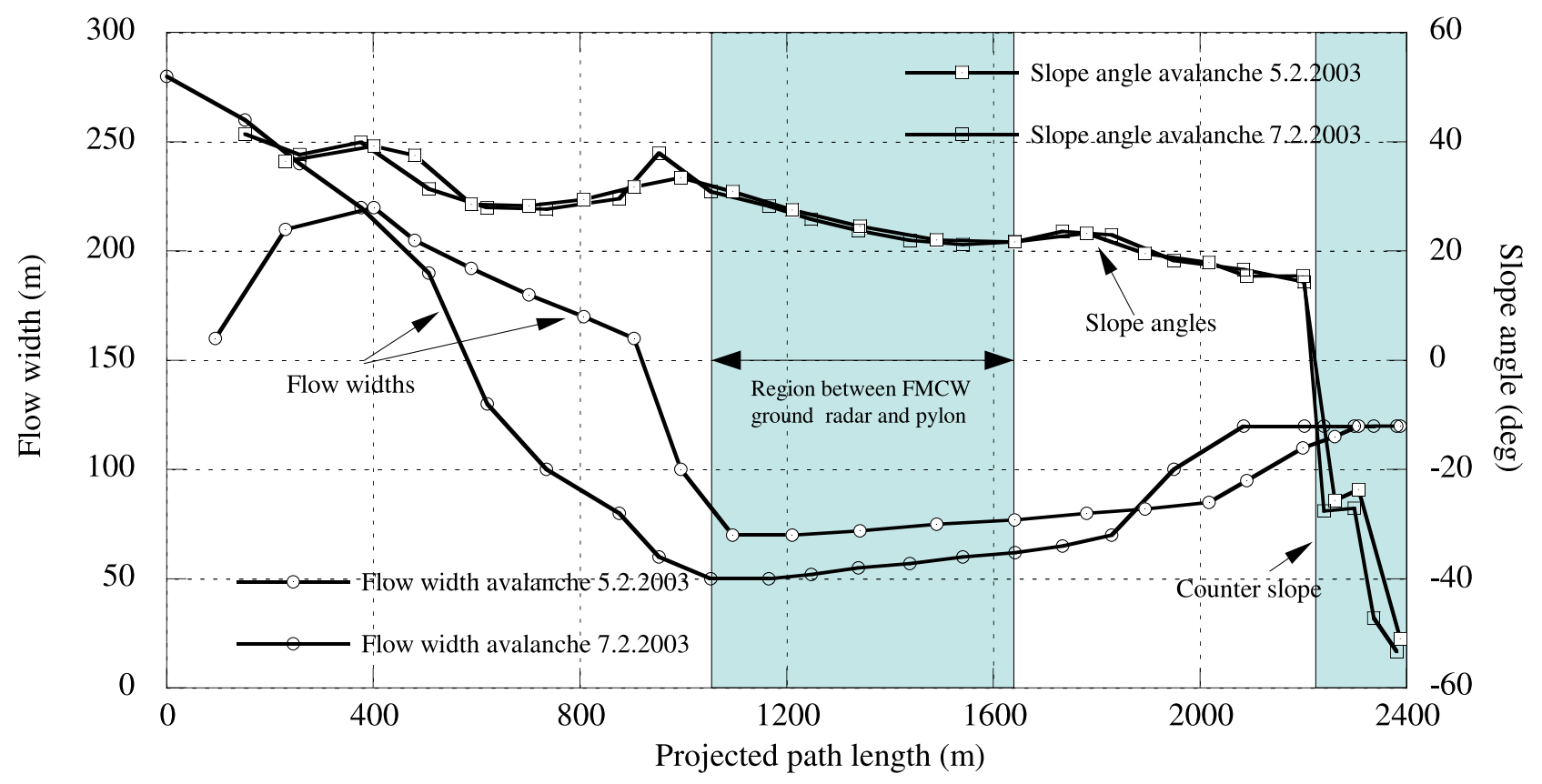

Figure 10. Slope angle and avalanche width of the Vallée de la Sionne events of 5 and 7 February 2003. The 7 February avalanche started about $100 \mathrm{~m}$ higher than the avalanche of 5 February.

Figure 7 shows an example of the numerical entrainment procedure. In this particular case, ploughing entrainment occurs at the avalanche front (the top layer is being entrained) and bed erosion behind the front. Thus the model allows for different entrainment processes to be simultaneously modeled along the length of the avalanche, depending on the properties of the snow cover and avalanche motion. The visualization of the entrainment and deposition processes is useful since the entrainment location can be observed and compared directly to field observations, when available.

[66] We assume that avalanches deposit snow when the mean flow velocity $U$ drops below a critical velocity $U_{c}$. Thus the volumetric snow deposition rate $\dot{S}_{d}$ is given by

$$
\begin{array}{ll}
\dot{S}_{d}(x, t)=0 & \text { for } \quad U(x, t) \geq U_{c} \\
\dot{S}_{d}(x, t)=C_{d} A(x, t) & \text { for } \quad U(x, t) U_{c}
\end{array}
$$

where the deposition coefficient $C_{d}$ varies between 0 and $1 \mathrm{~s}^{-1}$. Usually $C_{d}=1$, implying that the entire mass is deposited immediately once the avalanche falls below the critical velocity $U_{c}$. This procedure describes a stick/sliplike behavior commonly observed at the avalanche tail. We assume that the velocity distribution is nearly uniform over the flow height so that the entire mass stops suddenly. The critical velocity $U_{c}$ is set to $1 \mathrm{~m} / \mathrm{s}$.

[67] We expect the model to function poorly for wet snow avalanche flows as well as shortly after avalanche release, when the flow contains large blocks of the fracture slab. For this latter case, a plug-flow model, in which Coulombfriction controls the sliding-block nature of the flow, is more appropriate [Salm, 1993]. We also expect the model to function poorly when the mass loss to the powder cloud is significant and the essential nature of the flow changes from a dense flowing avalanche to a turbulent powder suspension flow. This procedure can be implemented within the framework of most numerical avalanche dynamics models. It essentially requires modification of the righthand sides of the mass equation of depth-averaged theories.

\subsection{Model Simulations}

[68] In the experimental section we observed that entrainment plays an important role for determining the run-out distances, and in particular we observed that avalanches that have same velocities in some cases reached completely different run-out distances. This effect is practically impossible to obtain with models which do not consider entrainment and whose velocities and run-out distances are practically proportional to the release mass. We want to demonstrate here that the avalanche simulation is more reliable when entrainment is correctly implemented into a numerical model.

[69] For this purpose we back-calculate two events observed at the Vallée de la Sionne experimental site during the winter season 2003-2004. These are avalanches 5 and 6, which occurred on 5 and 7 February 2003, respectively [Sovilla et al., 2004]. They are interesting for the following reasons.

[70] 1. The avalanches followed similar trajectories. An overview of the avalanches is shown in Figure 9. The slope profiles of the avalanches are shown in Figure 10. Avalanche 6 started about $100 \mathrm{~m}$ higher $(2615 \mathrm{~m}$ a.s.1.) than avalanche 5 (2540 $\mathrm{m}$ a.s.l.).

[71] 2. They have similar initial conditions. The release of avalanche 6 (about $7300 \mathrm{t}$ ) was the natural extension of avalanche 5 (about 11,150 t). On the basis of photogrammetric measurements, we observed that the avalanche slabs had release boundaries in common and both slid over the same surface. No significant precipitation followed avalanche 5. Snow characteristics were similar. 


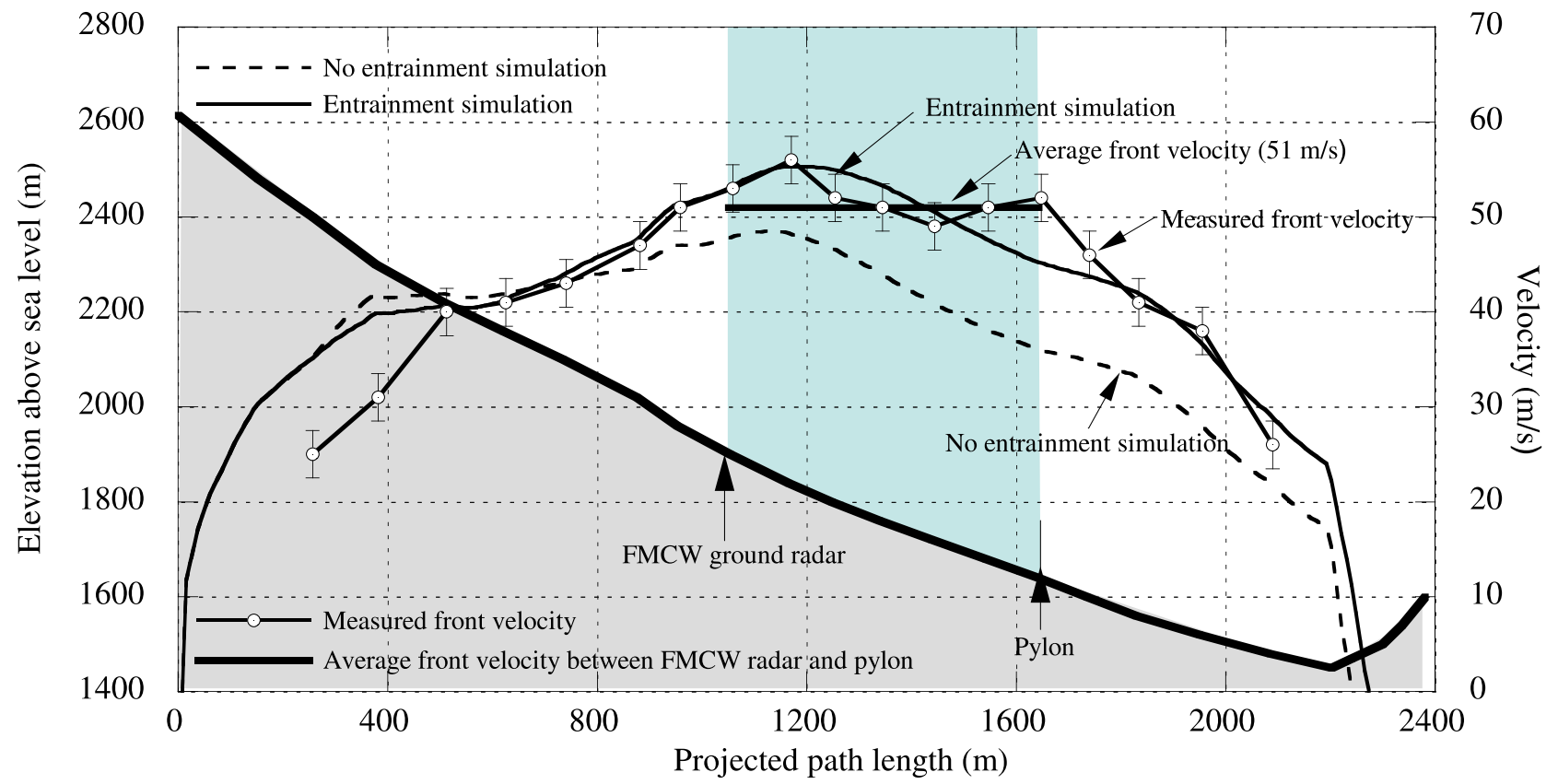

Figure 11. Maximum velocity simulations of the Vallée de la Sionne event of 7 February 2003. Simulations with and without entrainment are compared to the observed data. Note that velocities calculated with entrainment are in good agreement with observed data.

[72] 3. They have similar velocities. The front velocity of avalanche 6 was measured by video analysis. It was not possible to measure the front velocity of avalanche 5 since it released naturally. However, it was possible to measure average speeds between the FMCW radar at $1892 \mathrm{~m}$ a.s.l. and the mast at $1642 \mathrm{~m}$ a.s.l. of $49 \mathrm{~m} / \mathrm{s}$ and avalanche $651 \mathrm{~m} / \mathrm{s}$. Front velocities were also measured at $1892 \mathrm{~m}$ a.s.l. by the $\mathrm{FMCW}$ radar pair: Avalanche 5 had a speed of $43-50 \mathrm{~m} / \mathrm{s}$ (uncertainties in the signal) and avalanche 6 was about $50 \mathrm{~m} / \mathrm{s}$.

[73] 4. They have different entrainments. The majority of the snow cover was entrained by avalanche 5 (Figure 1, left). At the radar location, avalanche 5 entrained about 1.3 $\mathrm{m}$ of snow while avalanche 6 (Figure 1, right) entrained only $0.30 \mathrm{~m}$. Front entrainment was dominating. These are local values and are different from the average entrainment depth $d_{e}$ reported in Table 3.

[74] 5. They have different run-outs. Avalanche 5 reached the bottom of the valley and climbed the opposite slope partially covering the bunker. Avalanche 6 reached the valley bottom and stopped against the opposite slope; the slower avalanche had a longer run-out distance.

[75] For the simulation with entrainment, release depth, $d_{0}$, entrainment depth, $d_{e}$, and densities, $\rho_{0}=\rho_{e}$, were defined according to Table 3; that is, simulations were performed by defining only one homogeneous erodible snow layer.

[76] We used $p^{*}(x)$ values on the order of $1 \mathrm{kPa}$. This value provided the correct entrainment rates within the framework of the Grigorian and Ostroumov entrainment model. However, this value has no physical basis. Measured shear and normal stress strength values for snow are smaller, especially for new snow. The parameter $p^{*}(x)$ must account for a complex series of processes, including snow cover fracture, decomposition and compression at high strain rates, that cannot be directly measured with simple mechanical tests. Further investigations should attempt to find a physical basis for this important parameter. In the simulations, all the erodible snow cover was entrained at the avalanche front as observed from the FMCW plots.

[77] Both avalanches were back calculated using the calibration parameters: $b=0.25, s=0.4, m_{x y}=0.085, m_{x x}$ $=5$ and $m_{y y}=0.05$ which where chosen to match measured velocities between the radar and the pylon and to approximately fit the run-out/run-up distance. The run-out/run-up of these avalanches was influenced by the opposite slope. Uncertainties concerning the energy dissipations produced during the impact of avalanches with obstacles remain: Avalanche models do not account for energy dissipations arising from the formation of shock waves, and calculated run-out/run-up are still imprecise.

[78] The same calibration parameters and initial conditions were used for the simulations without entrainment. The simulation results are shown in Figures 11, 12 and 13.

[79] Figure 11 shows the maximum velocity simulations of the Vallée de la Sionne event of 7 February 2003. Simulations with entrainment are compared to the observed avalanche front velocities.

[80] Figure 12 shows the maximum velocity simulations of the 5 February event. Simulated velocities with entrainment are compared to the average avalanche velocity measured between the FMCW radar and the pylon.

[81] Note that it was possible to back-calculate the velocities using the same set of calibration parameters for both avalanches. In Figure 11, only the velocities below the release area are higher than the measured.

[82] A comparison between the two simulations (Figure 13) shows that in spite of its lower speed, the 5 February avalanche reaches a longer run-out as observed in reality. Simulations without entrainment (Figures 11 


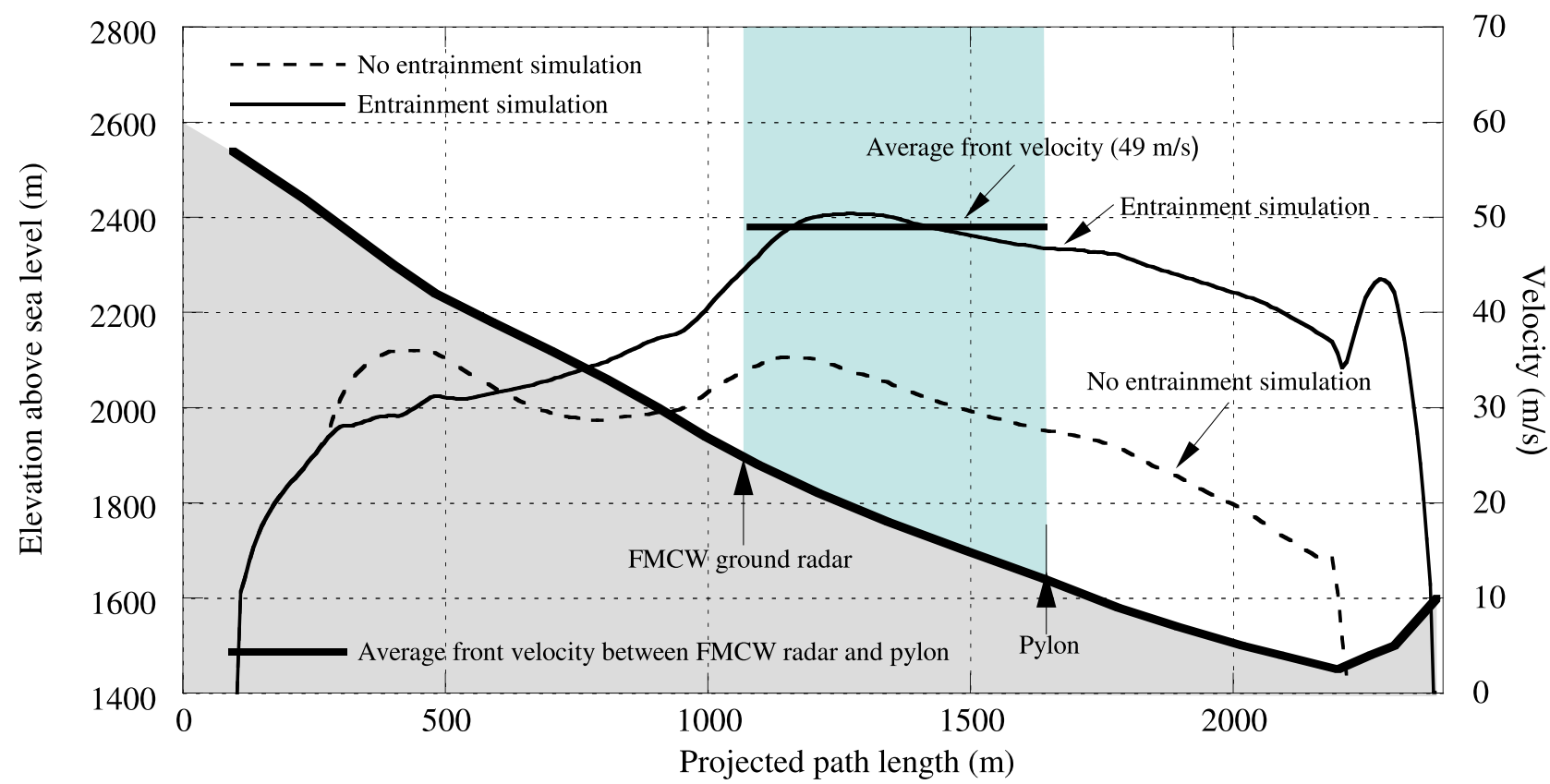

Figure 12. Maximum velocity simulations of the Vallée de la Sionne event of 5 February 2003. Simulations with and without entrainment are compared to the average front velocity measured between altitudes 1892 (FMCW radar) and 1642 (pylon) m a.s.l.

and 12) demonstrate that this effect cannot be obtained if entrainment is not introduced in the model. Using the same calibration parameters as in the case with entrainment, the 7 February avalanche, for effects of its larger initial mass and consequently higher velocity, reaches a longer run-out in comparison to the 5 February avalanche, in contradiction to what is observed in the field.
Note that the overall quality of the simulations without entrainment could be improved to better fit measured velocities by choosing different calibrations parameters. However, the problem with the run-out would remain.

[83] To understand why the model with entrainment is able to reproduce correct avalanche velocity and run-out, the potential $P(t)$ and kinetic $K(t)$ energies of the avalanche

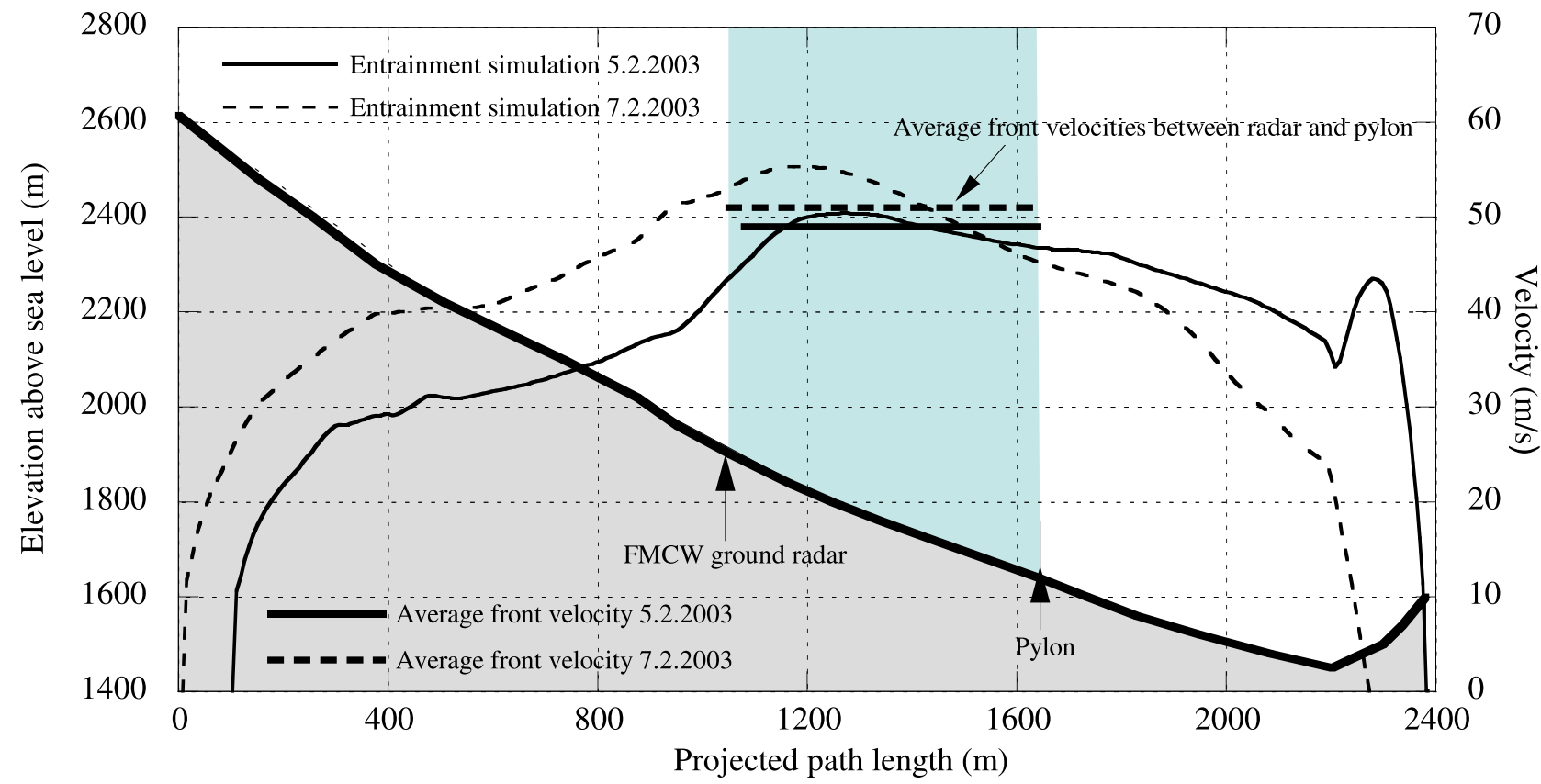

Figure 13. Comparison between maximum velocity simulations of the Vallée de la Sionne events of 5 and 7 February 2003. Simulations with entrainment are compared to the average front velocities measured between altitudes 1892 (FMCW radar) and 1642 (pylon) m a.s.l. 


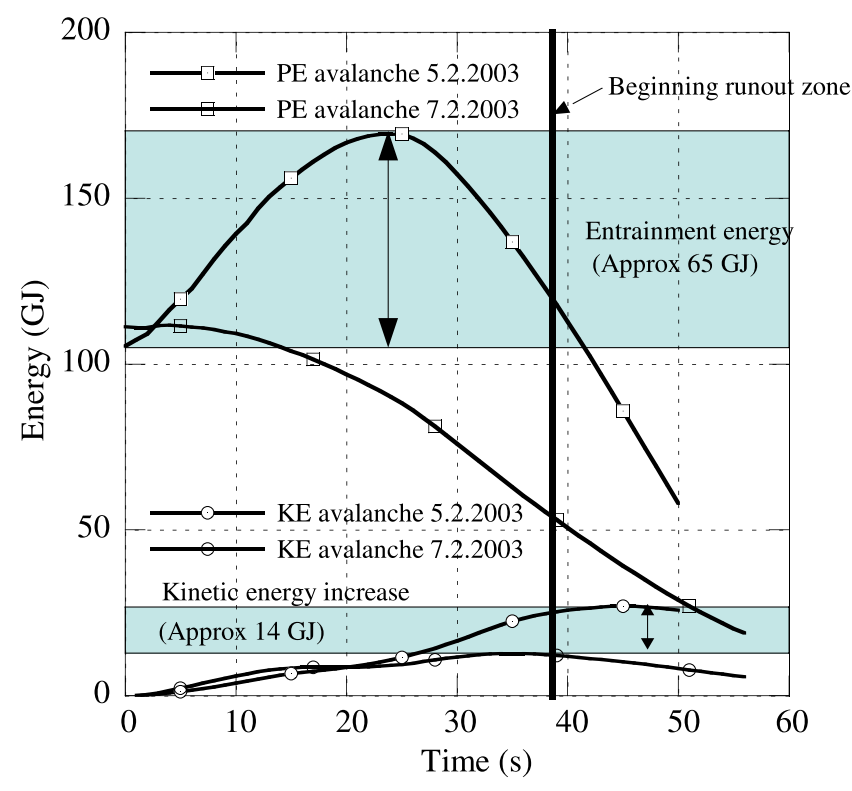

Figure 14. Calculated kinetic $K(t)$ and potential $P(t)$ energy of the 5 and 7 February 2003 avalanches.

are calculated using the model described in the previous section. For each time step $t, P(t)$ and $K(t)$ are calculated using the relation

$$
P(t)=\sum_{i=1}^{n} m_{i}(t) g H_{i}(t) ; \quad K(t)=\sum_{i=1}^{n} \frac{1}{2} m_{i}(t) U_{i}(t)^{2},
$$

where $n$ is the number of calculation cells that, at each instant $t$, are occupied by the avalanche, $g$ is the gravitational acceleration, $m_{i}$ and $H_{i}$ are, respectively, the cell mass and altitude with respect to the altitude reached by the run-out, and $U_{i}$ is the average velocity.

[84] The results of the calculations are shown in Figure 14. The vertical line in figure represents when the avalanche reached the beginning of the run-out (1640 $\mathrm{m}$ a.s.1.). The lines end when the avalanche reached the valley bottom.

[85] We calculated that, at the beginning of the run-out, in spite of the lower speed, the 5 February avalanche has about 2 times the kinetic energy of the 7 February avalanche. This produced its longer run-out as already seen in the measurements.

[86] The energy analysis shows another interesting trend. The larger the avalanche mass, the more efficient the system is, i.e., the more the potential energy converted into kinetic energy. For the same mass, the more efficient avalanches are the ones that entrain more.

[87] This is shown in Table 5, which summarizes the results of the Vallée de la Sionne avalanche back-calculations. To calculate the avalanches the models parameters were varied following these rules.

[88] 1. The parameter $b$ was decreased linearly with increasing avalanche mass; that is, to match the correct velocities and approximative run-out distances, the friction has to be diminished with increasing avalanche dimension.

[89] 2. The parameters $m_{x x}$ and $m_{y y}$ have to be increased with increasing avalanche dimension to simulate the high straining process that characterize large avalanches. In other words, the model, especially in the case in which avalanches are entraining at the avalanche front, tend to accumulate the mass at the front reaching unrealistically high flow depth. In reality, avalanches tend to strain, assuming a thin and long shape that can be well reproduced increasing the parameters above.

[90] 3. All others parameters have been assumed constant.Avalanches have been calculated using the parameter combinations shown in Table 5.

[91] The energy analysis makes evident the huge power of the 25 February 1999 avalanche; the maximum kinetic energy reached $40 \%$ of the maximum potential energy. This energy allowed the avalanche to travel for about $1.4 \mathrm{~km}$ along the valley bottom. This was the most efficient of the observed avalanches. The efficiency decreases with decreasing avalanche mass; the minimum is reached by the 30 January 1999 event (8.5\%). Between avalanches with the same maximum potential energy (10 February 1999 and 31 January $2003, b$ ) the more efficient is the avalanche that entrains more (10 February 1999). In fact, entrainment influences the flow depth distribution, and the avalanche that entrains more reaches higher flow depths.

[92] The model contains a friction slope which is inversely proportional to the flow height of the avalanche. That is, the higher the flow height, the smaller the flow resistance. When mass is entrained at the front of the avalanche, the model predicts that the flow resistance decreases at the front and the avalanche flows longer as observed from the experimental data. For obvious reasons, the same holds true for large avalanches (see Table 5 for an overview of the maximum calculated flow depths).

\section{Conclusion}

[93] We conclude by summarizing our primary results.

[94] 1. Observations of experimental and natural avalanches show a large increase in mass due to entrainment.

Table 5. Summary of Parameters Used to Back-Calculate the Vallée de la Sionne Avalanches ${ }^{\mathrm{a}}$

\begin{tabular}{|c|c|c|c|c|c|c|c|c|c|c|}
\hline $\begin{array}{c}\text { Date, } \\
\text { dd.mm.yy }\end{array}$ & $\mathrm{b}$ & $\mathrm{s}$ & $\mathrm{m}_{x y}$ & $\mathrm{~m}_{x x}$ & $\mathrm{~m}_{z z}$ & $\begin{array}{c}\text { Max } \\
\text { Velocity, m/s }\end{array}$ & $\begin{array}{c}\text { Max Flow } \\
\text { Depth, m }\end{array}$ & $\operatorname{Max} P, \mathrm{GJ}$ & $\operatorname{Max} K, \mathrm{GJ}$ & Efficiency, \% \\
\hline 30.01 .99 & 0.20 & 0.4 & 0.085 & 0.1 & 0.001 & 52 & 2.1 & 117 & 10 & 8.5 \\
\hline 10.02 .99 & 0.20 & 0.4 & 0.085 & 15 & 0.15 & 55 & 4.7 & 309 & 73 & 24 \\
\hline 25.02 .99 & 0.10 & 0.4 & 0.085 & 25 & 0.25 & 70 & 7.5 & 1610 & 645 & 40 \\
\hline $31.01 .03-\mathrm{a}$ & 0.25 & 0.4 & 0.085 & 5 & 0.05 & 43 & 2.8 & 52 & 6 & 12 \\
\hline $31.01 .03-b$ & 0.20 & 0.4 & 0.085 & 15 & 0.15 & 55 & 3.0 & 300 & 56 & 19 \\
\hline 05.02 .03 & 0.25 & 0.4 & 0.085 & 5 & 0.05 & 50 & 3.0 & 170 & 27 & 16 \\
\hline 07.02 .03 & 0.25 & 0.4 & 0.085 & 5 & 0.05 & 55 & 1.9 & 112 & 13 & 12 \\
\hline
\end{tabular}

${ }^{\mathrm{a}} \mathrm{A}$ synthesis of the results is also shown. 
If entrainment is not included in avalanche dynamics calculations, the energy balance is often incorrect. Since most calculation methods rely only on release mass, modifications to calculation guideline procedures are required.

[95] 2. Ploughing and step entrainment were the dominant snow uptake mechanisms in the Vallée de la Sionne avalanches. Entrainment is governed by the availability of mass. The structure of the snow cover (new snow layers, ice crusts) is more important than topographic features (slope angle, surface roughness) and determines how much mass is entrained. Parameterizing mass uptake using topographic features is of secondary importance in comparison to determining the structure of snow cover (new snow, sliding surfaces).

[96] 3. Although the Vallée de la Sionne avalanches reached similar average velocities (between $40 \mathrm{~m} / \mathrm{s}$ and $50 \mathrm{~m} / \mathrm{s}$ ), they had completely different run-out distances. Run-out distances are determined by the kinetic energy of the avalanche as it enters the run-out zone. Subsequently, the larger the mass of the avalanche, the greater the run-out distance, for equal velocity. Where the avalanche gets its mass is important. Avalanches that entrain more mass along the avalanche track exhibit higher kinetic energies (and therefore larger run-out distances) than avalanches that start with the same mass in the release zone. Thus it is necessary to correctly determine the avalanche mass in order to predict run-out distances, but not necessarily avalanche velocities.

[97] 4. We could not use an empirically based constitutive law, i.e., a Voellmy fluid that neglects internal shear deformations, to simulate avalanches with entrainment. The NIS model which includes internal deformations was more suited to simulate the distribution of mass within the avalanche, and consequently flow heights and velocities. Thus we speculate that entrainment modifies the internal shear rates such that viscous (or dilatant) fluidization effects cannot be neglected. However, the NIS model cannot accurately follow the initial stage of flow. In this case the measured velocities are much higher than the modeled velocities.

[98] These points lead us to believe that entrainment is a fundamental physical process in snow avalanches that can no longer be ignored and speculated upon. If a concept can be devised to define how much mass is available to be entrained, simple entrainment models (frontal ploughing) are adequate to describe the overall mass and energy balance of an event. This is certainly helpful. However, the numerical models are still empirically based and do not describe the complex internal flow mechanics of snow avalanches. In future, advanced models and detailed experiments will be required to understand how entrained mass is accelerated and distributed within the avalanche.

[99] Acknowledgments. Funding for this research has been provided by the Swiss National Foundation. The authors would like to thank the avalanche dynamic team and logistics staff of the SLF for their support in both the field and laboratory experiments.

\section{References}

Ammann, W. (1999), A new Swiss test site for avalanche experiments in the Vallée de la Sionne/Valais, Cold Reg. Sci. Technol., 30, 3-11.

Bartelt, P., B. Salm, and U. Gruber (1999), Calculating dense-snow avalanche run-out using a Voellmy fluid model with active/passive longitudinal straining, J. Glaciol., 45(150), 242-254.
Dent, J. D. (1993), The dynamic friction characteristics of a rapidly sheared granular material applied to the motion of snow avalanches, Ann. Glaciol., 18, 215-220.

Eglit, M., and K. Demidov (2005), Mathematical modeling of snow entrainment in avalanche motion, Cold Reg. Sci. Technol., 43, 10-23.

Eidgenössische Institut für Schnee- und Lawinenforschung (2000), Der Lawinenwinter 1999: Ereignisanalyse, Davos Dorf, Switzerland.

Gauer, P., and D. Issler (2004), Possible erosion mechanisms in snow avalanches, Ann. Glaciol., 38, 384-392.

Grigorian, S. S., and A. V. Ostroumov (1977), Matematicheskaya model sklonovih processov lavinnogo tipa (The mathematical model for slope processes of avalanche type), Sci. Rep. 1955, Inst. for Mech., Moscow State Univ., Moscow.

Gruber, U. (1998), Der Einsatz numerischer Simulationsmethoden in der Lawinengefahrenkartierung, Ph.D. thesis, Univ. of Zurich, Zurich.

Gruber, U., and P. Bartelt (2001), Study of the 1999 avalanches in the Obergoms valley, Switzerland, with respect to avalanche hazard mapping, paper presented at International Snow Science Workshop, Am. Avalanche Assoc., Montana State Univ., Bozeman.

Gruber, U., F. Dufour, D. Issler, M. Schaer, N. Dawes, M. Hiller, and V. Stoeckli (2002), Avalanche dynamics experimental site Vallée de la Sionne, Arbaz, Vallais: Final report winter 1998/1999, Tech. Rep. 732, Eidg. Inst. für Schnee- und Lawinenforschung, Davos Dorf, Switzerland. Gubler, H. (1987), Measurements and modelling of snow avalanche speeds, in Avalanche Formation, Movement and Effects: Proceedings of the Davos Symposium, September 1986, vol. 162, edited by B. Salm and H. Gubler, pp. 405-420, IAHS Press, Wallingford, UK.

Gubler, H., and M. Hiller (1984), The use of microwave FMCW radar in snow and avalanche research, Cold Reg. Sci. Technol., 9, 109-119.

Hungr, O. (1995), A model for the run-out analysis of rapid flow slides, debris flow, and avalanches, Can. Geotech. J., 32, 610-623.

Issler, D. (1999), European avalanche test sites: Overview and analysis in view of coordinated experiments, Mitt. 59, Eidg. Inst. für Schnee- und Lawinenforschung, Davos Dorf, Switzerland.

Kern, M., F. Tiefenbacher, and J. Mcelwain (2004), The rheology of snow in large chute flows, Cold Reg. Sci. Technol., 39, 181-192.

Naaim, M., T. Faug, and F. Naaim-Bouvet (2003), Dry granular flow modelling including erosion and deposition, Surv. Geophys., 24, 569-585.

Norem, H., F. Irgens, and B. Schieldrop (1989), Simulation of snow-avalanche flow in run-out zones, Ann. Glaciol., 13, 218-225.

Sailer, R., L. Rammer, and P. Sampl (2002), Recalculation of an artificially released avalanche with SAMOS and validation with measurements from a pulsed Doppler radar, Nat. Hazards Earth Syst. Sci., 2, 211-216.

Salm, B. (1993), Flow, flow transition and run-out distances of flowing avalanches, Ann. Glaciol., 18, 221-226.

Sartoris, G., and P. Bartelt (2000), Upwinded finite difference schemes for dense snow avalanche modeling, Int. J. Numer. Meth. Fluids, 32(7), $799-821$.

Sommavilla, F., and B. Sovilla (1998), The avalanche monitoring system of Mount Pizzac, in 25 Years of Snow Avalanche Research, Voss, 12-16 May 1998: Proceedings, vol. 203, edited by E. Hestnes, pp. 268-273, Norw. Geotech. Inst., Oslo.

Sovilla, B. (2004), Field experiments and numerical modelling of mass entrainment and deposition processes in snow avalanches, Ph.D. thesis, Swiss Fed. Inst. of Technol., Zurich.

Sovilla, B., F. Sommavilla, and A. Tomaselli (2001), Measurements of mass balance in dense snow avalanche events, Ann. Glaciol., 32, 230-236.

Sovilla, B., U. Gruber, F. Tiefenbacher, A. Felber, M. Maggioni, P. Bartelt, and F. Dufour (2004), Avalanche dynamics experimental site Vallée de la Sionne, Arbaz, Vallais: Final report winter 2002/2003, Tech. Rep. 750, Eidg. Inst. für Schnee- und Lawinenforschung, Davos Dorf, Switzerland. Tiefenbacher, F., and M. A. Kern (2004), Experimental devices to determine snow avalanche basal friction and velocity profiles, Cold Reg. Sci. Technol., 38, 17-30.

Vallet, J., U. Gruber, and F. Dufour (2001), Photogrammetric avalanche volume measurements at Vallée de la Sionne, Switzerland, Ann. Glaciol., $32,141-146$.

Vallet, J., B. Turnbull, S. Joly, and F. Dufour (2004), Observations on powder snow avalanches using videogrammetry, Cold Reg. Sci. Technol., $39,153-159$

P. Bartelt and B. Sovilla, Swiss Federal Institute for Snow and Avalanche Research, Flüelastrasse 11, CH-7260 Davos Dorf, Switzerland. (bartelt@ slf.ch; sovilla@slf.ch)

P. Burlando, Institute for Hydromechanics and Water Resources Management, ETHZ, Swiss Federal Institute for Science and Technology, Wolfgang-Pauli-Str. 15, CH-8093 Zurich, Switzerland. (burlando@ifu. baug.ethz.ch) 